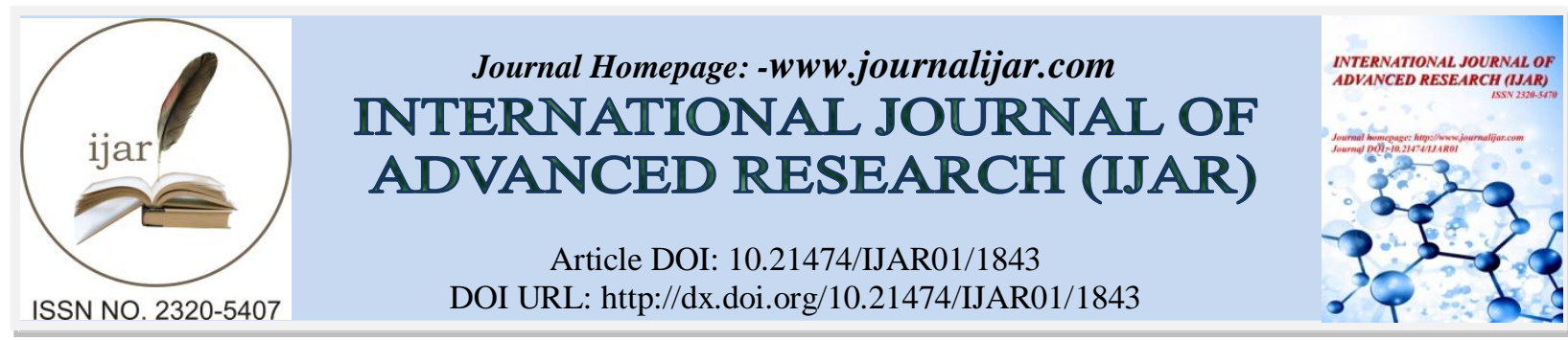

RESEARCH ARTICLE

\title{
MOLECULAR STRUCTURE, FTIR, FT-RAMAN, NBO ANALYSIS, FIRST ORDER HYPERPOLARIZABILITIES, THERMODYNAMIC FUNCTIONS AND NMR CHEMICAL SHIELDING ANISOTROPY (CSA) PARAMETERS OF METHYL 2-CHLORONICOTINATE BY AB INITIO DFT CALCULATIONS.
}

Dr. P. Dinesh.

Department of Physics, Salem Sowdeswari College (Govt. Aided), Salem-10, India.

\section{Manuscript Info \\ Manuscript History \\ Received: 16 August 2016 \\ Final Accepted: 22 September 2016 \\ Published: October 2016}

Key words:-

methyl 2-chloronicotinate; FT-IR; FT-

Raman; NMR; DFT;

\section{Abstract}

In this work, FT-IR and FT-Raman spectra are recorded on the solid phase of methyl 2-chloronicotinate in the regions $4000-400 \mathrm{~cm}^{-1}$ and $3500-100 \mathrm{~cm}^{-1}$ respectively. The geometrical parameters, vibrational assignments, HOMO-LUMO energies and NBO calculations are obtained for the monomer and dimer of methyl 2-chloronicotinate from DFT (B3LYP) with 6-311++G (d, p) basis set calculations. Second order perturbation energies and electron density (ED) transfer from filled lone pairs of Lewis base to unfilled Lewis acid sites of methyl 2-chloronicotinate are discussed on the basis of NBO analysis. give the evidence for the formation of dimer entities in the title molecule. The theoretically calculated harmonic frequencies are scaled by common scale factor. The observed and the calculated frequencies are found to be in good agreement. The thermodynamic functions were obtained for the range of temperature 100-1000 K. The polarizability, first hyperpolarizability, anisotropy polarizability invariant has been computed using quantum chemical calculations. The chemical parameters were calculated from the HOMO and LUMO values. The NMR chemical shielding anisotropy (CSA) parameters were also computed for the title molecule.

Copy Right, IJAR, 2016,. All rights reserved.

\section{Introduction:-}

The biological importance of Chloronicotinate and their complexes have shown notable bioactivity as medicinal, physicochemical, chelating therapeutics and biological properties.They are found in nature [1,2] and they can also be obtained by means of diverse synthesis procedures [3]. Chloronicotinate derivatives act as powerful inhibitors of the anthelmintic and vitamins. We found out that the treatment of alkylidenecyanoacetates with the Vilsmeier Haack reagent [4]. It is known that the therapeutically administered drugs are a subject of considerable interest. But little is known about modification of the activities of most drugs that are potential ligands. The methyl 2-chloronicotinate derivate are mainly of great pharmacological and medicinal interest because they exhibit a wide range of anticancer activity [5-14],A recent study has linked such as hypnotic, anti-tubercular [15], analgesic [16], antiviral [17], antibacterial[18-22], anti-diabetic, anti-inflammatory and antitumor agents [23-26], and the mechanism of action attributed to each derivative are strongly depending on the type of modifications of methyl 2-chloronicotinate [2731]. To the best of our knowledge, no detailed spectroscopic investigation has been made on the title compound consideration of the above factors motivated us to undertake this detailed spectroscopic investigation. 
Considering the above mentioned aspects and the resulting demand of methyl 2-chloronicotinate has led to search for commercially attractive and flexible compounds and to investigate the entire properties. To the best of our knowledge, FTIR and FT-Raman vibrational studies on the fundamental modes and electronic property investigations by NBO analysis, frontier molecular orbitals (FMOs) and thermodynamic properties on methyl 2chloronicotinate are inadequate in the literature. This inadequacy observed in the literature motivated us to investigate on methyl 2-chloronicotinate by experimental techniques and theoretical methods. Thus, a detailed investigation have been attempted using DFT/B3LYP method with $6-311++\mathrm{G}(\mathrm{d}, \mathrm{p})$ basis set to provide more satisfactory and valuable information on electronic structure, molecular orbitals and potential energy distribution. The optimized geometry, FMO's and their energy gaps, molecular electrostatic potential contour (MESP), total density region and electro static potential contour (MESP) map have been constructed at B3LYP/6-311++G(d,p) level, in order to understand the electronic properties, electrophilic and nucleophilic active centers of methyl 2chloronicotinate.

\section{Experimental Details:-}

The methyl 2-chloronicotinate in the liquid (Clear - Slightly pale yellow - reddish yellow) were purchased from Lancaster Chemical Company, UK which is of spectroscopic grade and hence used for recording the spectra as such without any further purification to record FTIR and FT-Raman spectra. The FTIR compounds were recorded by $\mathrm{KBr}$ pellet method in the region $4000-400 \mathrm{~cm}^{-1}$ using BROKER IFS 66V spectrometer with a Globar source, $\mathrm{Ge} / \mathrm{KBr}$ beam splitter and a MCT detector. The frequencies for all sharp bands are accurate to $2 \mathrm{~cm}^{-1}$. The FT-Raman spectra were also recorded in the range $3500-50-\mathrm{cm}^{-1}$ by the same instrument with FRA 106 Raman module equipped with Nd:YAG laser source with $200 \mathrm{~mW}$ power operating at $1064 \mathrm{~nm}$. A liquid nitrogen cooled-Ge detector was used. The spectral resolution is $2 \mathrm{~cm}^{-1}$.

\section{Computational Details:-}

Quantum chemical calculation were used for methyl 2-chloronicotinate to carry out the optimized geometry and vibrational wavenumbers with the 2009 version of the Gaussian suite [32] using the DFT-B3LYP methods [33, 34] supplemented with standard $6-311++\mathrm{G}(\mathrm{d}, \mathrm{p})$ basis sets. The stability of the optimized geometries was confirmed by wavenumber calculations, which gave positive values for all the obtained wavenumbers. The vibrational modes were assigned by means of visual inspection using GAUSSVIEW 5.0.8 program [35]. A comparison is made between the theoretically calculated frequencies and the experimentally measured frequencies. In this investigation we observed that the calculated frequencies were slightly greater than the fundamental frequencies. To improve the agreement between the predicted and observed frequencies, the computed harmonic frequencies are usually scaled for comparison. In this work the force field was scaled according to the SQM procedure [36], the Cartesian representation of the force constants were transferred to a non-redundant set of local symmetry coordinates, chosen in accordance to the recommendations of Pulay et al. [37]. Calculation of the potential energy distribution (PED) and the prediction of IR intensities and Raman activities were done on a PC with the VEDA 4 program [38].The prediction of Raman intensities was carried out by following the procedure outlined below. The Raman activities (Si) calculated by Gaussian 09W and adjusted during scaling procedure with VEDA 4 program were converted to relative Raman intensity (Ii) using the following relation from the basic theory of Raman scattering [39, 40].

$$
I_{i}=\frac{f\left(v_{0}-v_{i}\right)^{4} S_{i}}{v_{i}\left[1-\exp \left(-h_{c} v_{i} / k T\right)\right]}
$$

Here, $v_{\mathrm{o}}$ is the exciting frequency $\left(\mathrm{cm}^{-1}\right), v_{\mathrm{i}}$ is the vibrational wavenumber of the $\mathrm{i}^{\text {th }}$ normal mode, $h, c$ and $k$ are universal constants, and $\mathrm{f}$ is the suitably chosen common scaling factor for all the peak intensities. Finally, the thermodynamic properties of the optimized structures were obtained theoretically from the harmonic vibrations.

\section{Result and Discussion:-}

\section{Structural descriptions:-}

The optimized geometry of methyl 2-chloronicotinate, using B3LYP/6-311++G $(\mathrm{d}, \mathrm{p})$ methods for various possible calculations. The structure optimization have shown that of Fig. 1 have produced the energyE $=-935.91257$ (A.U.). The most optimized structural parameters were also calculated by DFT method with different basis sets are depicted in Table 1. The optimized structural parameters were used to compute the vibrational frequencies of methyl 2chloronicotinate at the B3LYP/6-311 + $+\mathrm{G}(\mathrm{d}, \mathrm{p})$ level of calculations. 


\section{Vibrational assignments:-}

The geometry of the molecules under investigation is considered by possessing $\mathrm{C}_{1}$ point group symmetry and the optimized molecular structure is obtained from GAUSSAN 09W and GAUSSVIEW programs as shown in Fig. 1. The methyl 2-chloronicotinate consists of 17 atoms hence undergoes 45 fundamental modes of vibrations of each compound are distributed into the irreducible representations under $\mathrm{C}_{1}$ symmetry as 31 in-plane vibrations of $\mathrm{A}^{\prime}$ species and 14 out of plane vibrations of $\mathrm{A}^{\prime \prime}$ species.

$$
\text { i.e., } \Gamma_{\text {vib }}=31 \mathrm{~A}^{\prime}+14 \mathrm{~A}^{\prime \prime}
$$

All vibrations are active in both IR and Raman. The title molecule contains fluorine atom and carbonyl group with benzene ring. The experimental FTIR and FT-Raman spectra of methyl 2-chloronicotinate are given in Figs. 2 and 3, respectively.

All the calculated mode of vibrations is numbered from the largest to smallest within each fundamental wavenumber. The observed FT-IR and FT-Raman bands for various modes of vibrations are assigned and presented in Table 2. Comparison of the vibrational modes calculated at B3LYP with experimental values (Table 2) reveals that over estimation of the calculated vibrational modes of anharmonicity in the real system. Inclusion of electron correlation in the $6-311 \mathrm{G}++(\mathrm{d}, \mathrm{p})$ to a certain wavenumber data. The observed FT-IR and FT-Raman spectra of methyl 2-chloronicotinate are shown in Figs. 2 and 3, respectively. It is convenient to discuss the vibrational spectra of methyl 2-chloronicotinate in terms of characteristic spectral regions as described below.

\section{CH3 group vibrations:-}

The title compound possesses a single $\mathrm{CH}_{3}$ group in fourth position of the ring. The $\mathrm{CH}$ methyl group stretching vibrations are generally observed in the range 3000-2800 $\mathrm{cm}^{-1}$ [41,42]. For the assignments of $\mathrm{CH}_{3}$ group frequencies one can expect nine fundamentals viz., namely the symmetrical stretching in $\mathrm{CH}_{3}\left(\mathrm{CH}_{3}\right.$ sym. stretch), asymmetrical stretching $\left(\mathrm{CH}_{3}\right.$ asym. stretch), symmetrical $\left(\mathrm{CH}_{3}\right.$ sym. deform) and asymmetrical $\left(\mathrm{CH}_{3}\right.$ asy. deform) deformation modes, in-plane rocking $\left(\mathrm{CH}_{3} \mathrm{ipr}\right)$, out-of-plane rocking $\left(\mathrm{CH}_{3} \mathrm{opr}\right), \mathrm{CH}_{3}$ wagging $\left(\mathrm{CH}_{3}\right.$ wag.) and twisting $\left(\mathrm{CH}_{3}\right)$ modes. Methyl groups are generally referred as an electron donating substitution in the aromatic ring system.

The recorded FT-IR and FT-Raman spectra of methyl 2-chloronicotinate have strong and very weak intensity bands at 3160 and $3102 \mathrm{~cm}^{-1}$ and they are assigned to $\mathrm{CH}_{3}$ stretching vibrations of methyl 2-chloronicotinate. The $\mathrm{CH}_{3} \mathrm{ss}$ frequency is established at $3048 \mathrm{~cm}^{-1}$ in the FT-Raman spectrum of methyl 2-chloronicotinate. The methyl deformation modes mainly coupled with the in-plane bending vibrations and are also well established. The inplane methyl deformation mode of methyl 2-chloronicotinate is found at $1498 \mathrm{~cm}^{-1}$ in FT-IR spectrum. The band at 1460 $\mathrm{cm}^{-1}$ in FT-IR is attributed to $\mathrm{CH}_{3}$ out-of-plane deformation mode of methyl 2-chloronicotinate. The bands obtained at 1230 and $1192 \mathrm{~cm}^{-1}$ in FT-IR and FT-Raman spectra are assigned to $\mathrm{CH}_{3}$ in-plane and out-of-plane rocking modes, respectively. The contributions for all these modes are about $85 \%$. In the present study, they show good agreement with the calculated values.

\section{C-N vibrations:-}

The assignment of $\mathrm{C}-\mathrm{N}$ stretching frequency is a rather difficult ask since there are problems in identifying these frequencies fromother vibrations. Silverstein et al. [42] assigned C-N stretchingvibrations in the region 1382-1266 $\mathrm{cm}^{-1}$ for the aromatic amines. The bands obtained at 1352 and $1066 \mathrm{~cm}^{-1}$ in FT-Ramanspectrum and $1340 \mathrm{~cm}^{-1}$ in FTIR spectra have been assignedto $\mathrm{C}-\mathrm{N}$ stretching vibrations. The PED contribution results at thelast column of Table 2 show that, $\mathrm{C}-\mathrm{N}$ stretching vibrations (79\%)interacting considerably with $\mathrm{C}-\mathrm{C}(19 \%)$ stretching mode. In the present work, the observed value at $1095 \mathrm{~cm}^{-1}$ in FT-IR spectra isassigned to $\mathrm{C}-\mathrm{N}$ in-plane bending vibration. In the present study,the theoretically computed values belonging to $\mathrm{C}-\mathrm{N}$ stretchingvibrations are good agreement with spectral data.

\section{C-O vibrations:-}

Generally, the $\mathrm{C}-\mathrm{O}$ vibrations occur in the region $1260-1000 \mathrm{~cm}^{-1}$ [43]. In the present study, the $\mathrm{C}-\mathrm{O}$ stretching vibrationsare assigned at $1248,958 \mathrm{~cm}^{-1}$ in FT-Raman spectrum of methyl 2-chloronicotinate.According to the literature [44], the $\mathrm{C}-\mathrm{O}$ vibration is pushed tothe lower region by the influence of other vibrations, because ofthe proximity in methyl 2-chloronicotinate $\mathrm{C}-\mathrm{O}$ in plane bending vibration is found at $958 \mathrm{~cm}^{-1}$ in FT-Raman spectrum. 


\section{Ring vibrations:-}

In case of methyl 2-chloronicotinate, the carbon atoms coupled together in the hexagonalchain of ring possesses two C-C stretching vibrations at958, 859 and 978, 872 $\mathrm{cm}^{-1}$ in FT-IR and FT-Raman. The in-planeand out-of-plane bending vibrations of the benzene ring are generallyobserved below $1002 \mathrm{~cm}^{-1}[45]$ and these modes are not purebut they contributes drastically from other vibrations and are substituent-sensitive. In the title molecule, the ring in-plane (bring) andout-of plane (cring) bending modes are affected to a great extent bythe substituents and produce bands below $547 \mathrm{~cm}^{-1}$. From PED results, the bands present at 270 and $176 \mathrm{~cm}^{-1}$ in FT-Raman are assignedto $\mathrm{C}$ ring. The scaled theoretical wavenumbers correspondingto all the ring vibrations are found to have a good correlation withtheir available experimental observations.

\section{HOMO-LUMO Analysis:-}

In the first hyper polarizability value, there is an inverse relationship between first hyper polarizability and HOMOLUMO gap, allowing the molecular orbitals to overlap to have a proper electronic communication conjugation, which is a marker of the intramolecular charge transfer from the electron donating group through the p-conjugation system to the electron accepting group [46,47]. Many organic molecules, containing conjugated p-electrons characterized by large values of molecular first hyper polarizabilities were analyzed by means of vibrational spectroscopy [48, 49].

In most cases, even in the absence of inversion symmetry, the strongest bands in the Raman spectrum are weak in the IR spectrum and vice versa. But the intramolecular charge transfer from the donor to acceptor group through a single-double bond conjugated path can induce large variations of both the molecular dipole moment and the molecular polarizability, making IR and Raman intensity strong at the same time. The most important orbitals in a molecule are the frontier molecular orbitals, called HOMO and LUMO. These orbitals determine the way the molecule interacts with other species. The frontier orbital gap helps to characterize the chemical reactivity and kinetic stability of the molecule. A molecule with a small frontier orbital gap is more polarizable and is generally associated with a high chemical reactivity, low kinetic stability and is also termed as soft molecule [50]. The frontier molecular orbitals play an important role in the electric and optical properties [51]. The conjugated molecules are characterized by a small highest occupied molecular orbital-lowest unoccupied molecular orbital (HOMO-LUMO) separation, which is the result of a significant degree of intramolecular charge transfer from the end-capping electron-donor groups to the efficient electron-acceptor groups through p-conjugated path [52].

The HOMO represents the ability to donate an electron, LUMO as an electron acceptor represents the ability to obtain an electron. The HOMO and LUMO energy calculated by B3LYP/6-311G++(d,p) method is shown below. The energy gap between HOMO and LUMO is shown in Table 3 which shows that charge transfer may be taking place from methyl 2-chloronicotinate atom in Fig. 4. The energy difference between HOMO and LUMO orbital which is called as energy gap is a critical parameter in determining molecular electrical transport properties in DOS Spectrum analysis Fig. 5, because it is a measure electron conductivity calculated $-7.5558 \mathrm{eV}$ and $-2.0700 \mathrm{eV}$ for methyl 2-chloronicotinate, respectively.

Based on density functional descriptors global chemical reactivity descriptors of compounds such as hardness, chemical potential, softness, electronegativity and electrophilicity index as well as local reactivity have been defined [53-57, 32]. Pauling introduced the concept of electronegativity as the power of an atom in a compound to attract electrons to it. Hardness $(\eta)$, chemical potential $(\mu)$ and electronegativity $(\chi)$ and softness are defined follows.

$$
\begin{aligned}
& \eta=\frac{1}{2}\left(\frac{\partial^{2} E}{\partial N^{2}}\right)_{v(r)}=\frac{1}{2}\left(\frac{\partial \mu}{\partial N}\right)_{v(r)} \\
& \mu=\left(\frac{\partial E}{\partial N}\right)_{v(r)} \\
& \chi=-\mu=-\left(\frac{\partial E}{\partial N}\right)_{v(r)}
\end{aligned}
$$

Where, $E$ and $v(r)$ are electronic energy and external potential of an N-electron system respectively. Softness is a property of compound that measures the extent of chemical reactivity. It is the reciprocal of hardness.

$$
S=\frac{1}{\eta}
$$

Using Koop man's theorem for closed-shell compounds $\eta, \mu$ and $\chi$ can be defined as

$$
\eta=\frac{(1-A)}{2}
$$




$$
\begin{aligned}
& \mu=\frac{-(1+A)}{2} \\
& \chi=\frac{(1+A)}{2}
\end{aligned}
$$

Where, A and I are the ionization potential and electron affinity of thecompounds respectively. Electron affinity refers to the capability of a ligand to accept precisely one electron from a donor. However, in many kinds of bonding viz., covalent hydrogen bonding, and partial charge transfer takes place. Recently Parr et al. [53] have defined a new descriptor to quantify the global electrophilic power of the compound as electrophilicity index $(\omega)$, which defines a quantitative classification of the global electrophilic nature of a compound. Parr et al. [53] have proposed electrophilicity index $(\omega)$ as a measure of energy lowering due to maximal electron flow between donor and acceptor. They defined electrophilicity index $(\omega)$ as follows

$$
\omega=\frac{\mu^{2}}{2 \eta}
$$

The usefulness of this new reactivity quantity has been recentlydemonstrated in understanding the toxicity of various pollutants in terms of their reactivity and site selectivity $[32,58,59]$. The calculatedvalue of electrophilicity index describes the biological activity of methyl 2-chloronicotinate. All the calculated values of hardness, potential, softness andelectrophilicity index are shown in Table 3.

\section{Natural bond orbital (NBO) Analysis:-}

The NBO calculations were performed using NBO 3.1 program as implemented in the Gaussian 09W package at the DFT/B3LYP level in order to understand various second-order interactions between the filled orbitals of one subsystem and vacant orbitals of another subsystem, which is the measure of the delocalization or hyper conjugation. By the use of the second-order bond-antibond (donor-acceptor) NBO energetic analysis, insight in the most important delocalization schemes was obtained. The change in electron density (ED) of $(\sigma \square \square \pi \square)$ antibonding orbitals and E(2) energies have been calculated by natural bond orbital (NBO) analysis [60] using DFT method to give clear evidence of stabilization originating from various molecular interactions. NBO analysis has been performed on methyl 2-chloronicotinate in order to elucidate intramolecular hydrogen bonding, intramolecular charge transfer (ICT) interactions and delocalization of p-electrons of the benzene ring. The hyperconjugative interaction energy was deduced from the second-order perturbation approach [61]. For each donor (i) and acceptor $(\mathrm{j})$, the stabilization energy E2 associated with the delocalization $\mathrm{i} \rightarrow \mathrm{j}$ is estimated as

$$
E^{(2)}=\Delta E_{i j}=q_{i} \frac{F(i, j)^{2}}{\varepsilon_{i}-\varepsilon_{j}}
$$

Where $\mathrm{q}_{\mathrm{i}}$ is the donor orbital occupancy, $\square_{\mathrm{i}}$ and $\square_{\mathrm{j}}$ are diagonal elements and $\mathrm{F}(\mathrm{i}, \mathrm{j})$ is the off diagonal NBO Fock matrix element. The most important interactions between Lewis and non-Lewis orbitals with oxygen lone pairs are the second order perturbation energy values, $\mathrm{E}(2)$, corresponding to these interactions, and the overlap integral of each orbital pair. The second order perturbation theory analysis of Fock matrix in NBO basis of methyl 2chloronicotinate (Table 4-5) also indicates intramolecular interactions due to the orbital overlap of

(C3- C4) and $\square \square$ (C2- C3), resulting in high electron density (approx. 0.069e) of anti-bonding $\square$ orbitals (CC). The intra-molecular charge transfer from $\mathrm{O}$ atom of the $\mathrm{CO}-\mathrm{CH} 3$ group to the $\mathrm{C}-\mathrm{C}$ bond of benzene ring is also apparent from the MEP plot in Fig. [6,7,8]. The orbital overlap between $\square$ (C4- C5) and $\square \square$ (C3- C8) results in intramolecular charge transfer causing stabilization of the system. The charge transfer from $\square$ (C4- C5) to $\square \square$ (N1C6) amounts to the stabilization of $28.89 \mathrm{kcal} / \mathrm{mol}$. The magnitude of charge transfer from the lone pairs of $\mathrm{O} 9$ to antibonding $\square$ (C2 - C3) and $\square$ (C4- C5), $\square$ orbitals amount to stabilization of 20.78 and $19.39 \mathrm{kcal} / \mathrm{mol}$, respectively.

\section{Molecular electrostatic potentials (MEP):-}

Molecular electrostatic potential used extensively for interpreting potentials have been and predicting the reactive behavior of a wide variety of chemical system in both electrophilic and nucleophilic reactions, the study of biological recognition processes and hydrogen bonding interactions [62]. $\mathrm{V}(\mathrm{r})$, at a given point $\mathrm{r}(\mathrm{x}, \mathrm{y}, \mathrm{z})$ in the vicinity of a molecule, is defined in terms of the interaction energy between the electrical charge generated from the moleculeelectrons and nuclei and positive test charge (a proton)located at r. Unlike many of the other quantities used at present and earlier as indices of reactivity, $\mathrm{V}(\mathrm{r})$ is a real physical property that can be determined experimentally 
by diffraction or by computational methods. For the systems studied the MEP values were calculated as described previously, using the following equation[63]:

$$
V(r)=\sum \frac{Z_{A}}{\left|R_{A}-r\right|}-\int \frac{\rho\left(r^{\prime}\right)}{\left|r^{\prime}-r\right|} d r^{\prime}
$$

Where, the summation runs over all the nuclei $\mathrm{A}$ in the molecule andpolarization and reorganization effects are neglected. $\mathrm{Z}_{\mathrm{A}}$ is thecharge of the nucleus $\mathrm{A}$, located at $\mathrm{R}_{\mathrm{A}}$ and $\mathrm{q}(\mathrm{r} 0)$ is the electron densityfunction of the molecule.

To predict reactive sites for electrophilic and nucleophilic attack for the investigated molecule, the MEP at the B3LYP/6-311++G(d,p) optimized geometry was calculated. In the present study, the electrostatic potential (ESP), electron density (ED) and the molecular electrostatic potential (MEP) map figures for methyl 2-chloronicotinate are shown in Fig. [9-14]. The ED plots for title molecule show a uniform distribution. However, it can be seen from the ESP figures, that while the negative ESP is localized more over the oxygen atom and fluorine atoms and is reflected as a yellowish blob, the positive ESP is localized on the rest of the molecule. This result is expected, because ESP correlates with electro negativity and partial charges. In the majority of the MEPs, while the maximum negative region which preferred site for electrophilic attack indications as red color, the maximum positive region which preferred site for nucleophilic attack symptoms as blue color. The importance of MEP lies in the fact that it simultaneously displays molecular size, shape as well as positive, negative and neutral electrostatic potential regions in terms of color grading and is very useful in research of molecular structure with its physiochemical property relationship. The resulting surface simultaneously displays molecular size and shape and electrostatic potential value. In the present study, 3D plots of molecular electrostatic potential (MEP) of methyl 2-chloronicotinate has been draw in Fig. $[15,16]$. The MEP is a plot of electrostatic potential mapped onto the constant electron density surface. The different values of the electrostatic potential at the surface are represented by different colors. Potential increases in the order red <orange < yellow < green < blue. The negative (red1 and yellow) regions of the MEP are related to electrophilic reactivity and the positive (blue) regions to nucleophilic reactivity, as shown in Fig. 9.

\section{Thermodynamic properties:-}

On the basis of vibrational analysis, the statically thermodynamic functions: heat capacity $\left(C_{p, m}^{o}\right)$, enthalpy changes $\left(\Delta H_{m}^{o}\right)$ and entropy $\left(S_{m}^{o}\right)$ for the title molecule were obtained from the theoretical harmonic frequencies and listed in Table 6. From Table 6, it can be observed that these thermodynamic functions are increasing with temperature ranging from 100 to $1000 \mathrm{~K}$ due to the fact that the molecular vibrational intensities increases with temperature expect Gibb's free energy. The correlation equations between heat capacity, entropy, enthalpy changes, Gibb's free energy and temperatures were fitted by quadratic formulas and the corresponding fitting factors (R2) for these thermodynamic properties are 0.996, 0.9997 and 0.9995 , respectively. The corresponding fitting equations are as follows and the correlation graphics of those shown in Fig. 17.

$$
\begin{aligned}
& C_{p, m}^{o}=-5.0244+0.12021+6.5247 \times 10^{-5} T^{2}\left(R^{2}=0.9996\right) \\
& S_{m}^{o}=-4.2741+0.1544 T+58.0862\left(R^{2}=0.9997\right) \\
& \Delta H_{m}^{o}=3.2610+0.0192 T-1.4532\left(R^{2}=0.9995\right)
\end{aligned}
$$

All the thermodynamic data supply helpful information for the further study on the methyl 2chloronicotinate. They can be used to compute the other thermodynamic energies according to relationships of thermodynamic functions and estimate directions of chemical reactions according to the second law of thermodynamic theoretical harmonic frequencies and listed in Table 7.

\section{Chemical shielding anisotropy (CSA) parameters:-}

Nuclear magnetic resonance (NMR) spectroscopy is a powerfultool for the structure determination of large molecules. The NMRtechnique is based on the sensitively of magnetic properties, typicallyisotropic chemical shielding (ICS), to the chemical environmentof the nuclei. The full NMR shielding tensor in Fig. 18 (a) isnonsymmetrical and of rank 2, containing nine independent quantitiesare used to predict the CSA parameters defined by Czinkiet al. [64] as follows. The isotropic chemical shielding, $\alpha_{\text {iso }}$ one ofthe scalar invariants of the tensor, is given by $1 / 3$ of the trace of $(\alpha)$.

$$
\alpha_{i s o}=(1 / 3) \operatorname{Tr} \sigma=\left(\sigma_{x x}+\sigma_{y y}+\sigma_{z z}\right) / 3=\left(\sigma_{1}+\sigma_{2}+\sigma_{3}\right) / 3
$$

In NMR spectroscopy the concept of anisotropy was advanced fromthe theory of axially symmetric tensors, where two principal componentshave the same value. The anisotropy $(\Delta)$ is the differenceof the two distinct components in this generalization, 


$$
\Delta=\sigma_{3}-\left(\sigma_{1}+\sigma_{2}\right) / 2=3\left(\sigma_{3}-\sigma_{i s o}\right) / 2
$$

The asymmetry $(\eta)$ was intended to show the deviation from theaxially symmetric tensor,

$$
\eta=\left(\sigma_{2}-\sigma_{1}\right) /\left(\sigma_{3}-\sigma_{\text {iso }}\right)
$$

In the case of an axially symmetric tensor, $\eta=0$ The CSA parameters,span $(\Omega)$ and skew $(\mathrm{k})$ of the shielding tensor arein Fig. 19,

$$
\Omega=\sigma_{3}-\sigma_{1}(\Omega \geq 0)
$$

and

$$
k=3\left(\sigma_{2}-\sigma_{\text {iso }}\right) / \Omega=\left(2 \sigma_{2}-\sigma_{1}-\sigma_{3}\right) / \Omega(-1 \leq k \leq+1)
$$

where the principal components (Eigen values of $\sigma^{\mathrm{s}}$ ) are labeledaccording to $(-1 \leq k \leq+1)$.

The symmetric Eigen values are obtainedfrom the following relations,

$$
\begin{aligned}
& \sigma_{1}=\sigma_{\text {iso }}-\Omega(k+3) / 6 \\
& \sigma_{2}=\sigma_{\text {iso }}+\Omega k / 3 \\
& \sigma_{3}=\sigma_{\text {iso }}-\Omega(k-3) / 6
\end{aligned}
$$

The CSA parameters $(\rho)$ and $(\tau)$ describe the magnitude and orientationof the anisotropy, respectively

$$
(\rho)=\operatorname{sqrt}\left(\left[\left(\sigma_{1}-\sigma_{2}\right)^{2}+\left(\sigma_{1}-\sigma_{3}\right)^{2}+\left(\sigma_{2}-\sigma_{3}\right)^{2}\right] / 2\right)
$$

and

$$
\begin{aligned}
& (3 \tau)=k \pi+(-1)^{(k+1)} \arcsin (\bmod \mathrm{e}(\sigma)) \\
& (k=0, \pm 1, \pm 2, \pm 3)
\end{aligned}
$$

The CSA parameters $(\rho)$ and $(\tau)$ are also expressed in terms of $\operatorname{span}(\Omega)$ and skew $(\mathrm{k})$ are as follows

$$
(\rho, \tau)=\left(\left(\frac{\Omega}{2} \sqrt{3+k^{2}}\right), \arcsin \left[\frac{k\left(9-k^{2}\right)}{\left(3+k^{2}\right)^{\frac{3}{2}}}\right]\right)
$$

Using the above said relations the complete nuclear magnetic resonance(NMR) chemical-shielding tensors, $r$, have been computed atdensity functional theory (DFT) and HF, within the gauge-includingatomic orbital (GIAO) formalism, for both structure of the moleculemethyl 2-chloronicotinate. The CSA parameters of the carbon nitrogen and hydrogenatoms of the molecule both in monomer and dimer are calculatedin DFT method with the level of B3LYP/6-311++G (d, p) and presentedin Table 8.

\section{Magnetic susceptibility:-}

Atoms, molecules, free radicals or ions which contain one or more unpaired electron will possess permanent magnetic dipole moment, that arises from the residual spin and angular momentum of the unpaired electrons. All substances having permanent magnetic moment display paramagnetic behavior in nature. When a paramagnetic substance is placed in a magnetic field, they will align themselves in the direction of the field and thus produces positive magnetic susceptibility, which depends on the temperature; since thermal agitation will oppose the alignment of the magnetic dipoles. The effectiveness of the field diminishes with increase in temperature. The magnetic susceptibility $\left(\chi_{\mathrm{m}}\right)$ of the molecules for various temperatures are predicted with knowledge of unpaired electron [65] and presented in Table 9. The graphical representation of $\left(\chi_{\mathrm{m}}\right)$ with $1 / \mathrm{T}$ (temperature $\left.{ }^{-1}\right)$ is shown in Fig. [20-22]. The effective magnetic moment is found to be a constant, which is $1.7063 \times 10^{-5}(\mathrm{BM})$ and the Curie constant is obtained from the magnetic moment $\left(\mu_{\mathrm{m}}\right)$ and is found to be $3.39174 \times 10^{-5}$.

\section{Natural Charges:-}

The total atomic charges of methyl 2-chloronicotinate molecule are obtained by Mulliken population analysis with B3LYP/6-311++G (d, p) basis set are listed in Table 10. From the results, it is clear that the substitution in methyl 
2-chloronicotinate leads to the redistribution of electron density. The $\sigma$ electron with drawing character of the $\mathrm{Cl} 7$ atom in methyl 2-chloronicotinate is demonstrated by the decrease in electron density on C3 atom. In methyl 2chloronicotinate the C8 atom is more acidic due to more positive charge. The Mulliken atomic charges of the methyl group hydrogen atoms are lesser than hydrogen atom. The graphical representation of atomic charges of the atoms obtained by B3LYP for methyl 2-chloronicotinate is shown in Fig. [23, 24].

Since the charge distribution on the molecule has an important influence on the vibrational spectra, the net charge distribution of methyl 2-chloronicotinate was calculated by the natural population analysis (NPA) method with B3LYP/6-311G++(d,p) basis sets and the charges are listed in Table 10. The corresponding NPA plot is shown in Fig. 24. The atomic charges of methyl 2-chloronicotinatecalculated by NPA analysis using B3LYP methods with 6-311++G(d,p) basis sets are presented in Table 10. Among the carbon atoms C3 and C5 have positive charge while C8 have negative charge.

Table 1:- Optimized geometrical parameters of methyl 2-chloronicotinate obtainedby B3LYP/6311++G(d,p) level calculations

\begin{tabular}{|c|c|c|c|c|c|}
\hline Bond Length & Value ( $)$ & Bond angle & Value ( ) & Dihedral Angle & Value (o) \\
\hline N1-C2 & 1.32 & C2-N1-C6 & 118.71 & C6-N1-C2-C3 & -0.36 \\
\hline N1-C6 & 1.34 & N1-C2-C3 & 123.75 & C6-N1-C2-C17 & 176.76 \\
\hline C2-C3 & 1.41 & N1-C2-C17 & 114.38 & C2-N1-C6-C5 & -1.65 \\
\hline C2-C17 & 1.76 & C3-C2-C17 & 121.80 & C2-N1-C6-H17 & 178.96 \\
\hline C3-C4 & 1.40 & C2-C3-C4 & 116.36 & N1-C2-C3-C4 & 2.39 \\
\hline C3-C8 & 1.50 & C2-C3-C8 & 127.66 & N1-C2-C3-C8 & -178.90 \\
\hline C4-C5 & 1.39 & C4-C3-C8 & 115.97 & C17-C2-C3-C4 & -174.53 \\
\hline C4-H15 & 1.08 & C3-C4-C5 & 120.34 & C17-C2-C3-C8 & 4.17 \\
\hline C5-C6 & 1.39 & C3-C4-H15 & 118.21 & C2-C3-C4-C5 & -2.48 \\
\hline C5-H16 & 1.08 & C5-C4-H15 & 121.45 & C2-C3-C4-H15 & 177.71 \\
\hline C6-H17 & 1.09 & C4-C5-C6 & 117.81 & C8-C3-C4-C5 & 178.66 \\
\hline C8-O9 & 1.21 & C4-C5-H16 & 121.36 & C8-C3-C4-H15 & -1.15 \\
\hline C8-O10 & 1.34 & C6-C5-H16 & 120.83 & C2-C3-C8-O9 & -148.57 \\
\hline O10-C11 & 1.44 & N1-C6-C5 & 122.96 & C2-C3-C8-O10 & 34.37 \\
\hline C11-H12 & 1.09 & N1-C6-H17 & 115.84 & C4-C3-C8-O9 & 30.14 \\
\hline C11-H13 & 1.09 & C5-C6-H17 & 121.20 & C4-C3-C8-O10 & -146.92 \\
\hline C11-H14 & 1.09 & C3-C8-O9 & 122.54 & C3-C4-C5-C6 & 0.71 \\
\hline & & C3-C8-O10 & 113.46 & C3-C4-C5-H16 & -179.24 \\
\hline & & O9-C8-O10 & 123.94 & H15-C4-C5-C6 & -179.49 \\
\hline & & C8-O10-C11 & 116.12 & H15-C4-C5-H16 & 0.56 \\
\hline & & O10-C11-H12 & 110.27 & C4-C5-C6-N1 & 1.46 \\
\hline & & O10-C11-H13 & 105.21 & C4-C5-C6-H17 & -179.17 \\
\hline & & O10-C11-H14 & 110.33 & H16-C5-C6-N1 & -178.58 \\
\hline & & H12-C11-H13 & 110.80 & H16-C5-C6-H17 & 0.78 \\
\hline & & H12-C11-H14 & 109.36 & C3-C8-O10-C11 & 179.70 \\
\hline & H13-C11-H14 & 110.82 & O9-C8-O10-C11 & 2.69 \\
\hline & & & & C8-O10-C11-H12 & 59.74 \\
\hline & & & & C8-O10-C11-H13 & 179.25 \\
\hline & & & & -61.17 \\
\hline
\end{tabular}


Table 2:- Detailed assignment of fundamental vibrations of methyl 2-chloronicotinate by normal mode analysis based on scaled quantum Mechanical force field

\begin{tabular}{|c|c|c|c|c|c|c|c|c|}
\hline \multirow[t]{3}{*}{ No. } & \multicolumn{2}{|c|}{$\begin{array}{c}\text { Observed } \\
\text { frequency }\left(\mathrm{cm}^{-1}\right)\end{array}$} & \multirow{2}{*}{\multicolumn{5}{|c|}{ Calculated frequency $\left(\mathrm{cm}^{-1}\right)$}} & \multirow{3}{*}{$\begin{array}{c}\text { Characterization of } \\
\text { normal modes with } \\
\text { PED }(\%)\end{array}$} \\
\hline & \multirow[t]{2}{*}{ FT-IR } & \multirow{2}{*}{$\begin{array}{c}\text { FT- } \\
\text { Raman }\end{array}$} & & & & & & \\
\hline & & & Unscaled & Scaled & $\begin{array}{c}I R \\
\text { Activity }\end{array}$ & $\begin{array}{l}\text { Raman } \\
\text { Activity }\end{array}$ & $\begin{array}{c}\text { Raman } \\
\text { Intensity }\end{array}$ & \\
\hline 1 & 3209 & 3216 & 3206 & 3215 & 5.80 & 188.60 & 333.72 & CH (99) \\
\hline 2 & 3180 & - & 3193 & 3185 & 2.91 & 166.73 & 345.01 & CH (99) \\
\hline 3 & - & 3160 & 3164 & 3162 & 12.16 & 123.00 & 227.11 & $\mathrm{CH}(99)$ \\
\hline 4 & - & 3102 & 3164 & 3104 & 9.67 & 77.33 & 138.65 & $\mathrm{CH}_{3 \text { ips }}(99)$ \\
\hline 5 & 3048 & - & 3129 & 3048 & 15.46 & 62.06 & 114.62 & $\mathrm{CH}_{3 \mathrm{ss}}(99)$ \\
\hline 6 & 3005 & - & 3054 & 3004 & 30.90 & 57.33 & 705.93 & $\mathrm{CH}_{3 \mathrm{ops}}(99)$ \\
\hline 7 & 1740 & - & 1763 & 1739 & 307.33 & 53.24 & 101.97 & $\mathrm{C}=\mathrm{O}(93)$ \\
\hline 8 & 1614 & 1621 & 1622 & 1616 & 90.49 & 40.90 & 406.35 & $\mathrm{CC}(84), b \mathrm{CN}(13)$ \\
\hline 9 & 1516 & - & 1590 & 1516 & 32.49 & 35.93 & 1190.56 & $\mathrm{CC}(85), b \mathrm{CH}(12)$ \\
\hline 10 & - & 1498 & 1496 & 1490 & 9.08 & 31.50 & 650.00 & $\mathrm{CH}_{\text {ipb }}(89)$ \\
\hline 11 & 1490 & - & 1484 & 1495 & 9.88 & 13.73 & 177.75 & $b \mathrm{CH}(65), \mathrm{R} t r i g d(19)$ \\
\hline 12 & - & 1487 & 1477 & 1486 & 26.67 & 12.76 & 2942.31 & $\mathrm{CH} 3_{\mathrm{sb}}(96)$ \\
\hline 13 & 1460 & & 1466 & 1460 & 3.91 & 10.80 & 166.37 & $\mathrm{CH}_{3}$ opb $(96)$ \\
\hline 14 & 1352 & 1340 & 1431 & 1351 & 130.96 & 9.90 & 154.13 & $\mathrm{CN}(79), b \mathrm{CC}(19)$ \\
\hline 15 & 1306 & - & 1317 & 1306 & 355.54 & 9.67 & 322.80 & $b \mathrm{OH}(80), b \mathrm{CO}(17)$ \\
\hline 16 & 1277 & 1280 & 1289 & 1278 & 3.28 & 9.46 & 261.65 & CC(81), Rasymd(15) \\
\hline 17 & 1248 & - & 1252 & 1248 & 56.12 & 7.37 & 172.05 & $\mathrm{CC}(70), \mathrm{CO}(17), \mathrm{CH}(13)$ \\
\hline 18 & - & 1230 & 1214 & 1228 & 31.52 & 7.36 & 159.97 & $\mathrm{CH}_{3 \mathrm{ipr}}(78)$ \\
\hline 19 & 1192 & - & 1170 & 1190 & 1.02 & 6.89 & 397.51 & $\mathrm{CH}_{3 \mathrm{opr}}(77)$ \\
\hline 20 & - & 1178 & 1166 & 1176 & 115.83 & 6.50 & 98.06 & $\mathrm{CC}(77), \mathrm{CC}(21)$ \\
\hline 21 & 1144 & - & 1143 & 1143 & 25.09 & 4.70 & 488.46 & CC(74), Rsymd(17) \\
\hline 22 & - & 1095 & 1080 & 1094 & 38.48 & 4.45 & 186.85 & $b \mathrm{C}=\mathrm{O}(73), b \mathrm{CC}(13)$ \\
\hline 23 & 1066 & - & 1077 & 1068 & 42.77 & 3.71 & 62.52 & $\mathrm{CN}(60), \mathrm{CC}(25), \mathrm{R} t r i g d(15)$ \\
\hline 24 & 1028 & - & 1002 & 1026 & 0.34 & 3.40 & 253.83 & $b \mathrm{CC}(72), \mathrm{CO}(13)$ \\
\hline 25 & - & 978 & 981 & 976 & 2.44 & 3.04 & 88.23 & $b \mathrm{CH}(85), \mathrm{CC}(12)$ \\
\hline 26 & 958 & - & 975 & 956 & 9.30 & 2.60 & 71.40 & $\mathrm{CO}(82)$ \\
\hline 27 & 834 & 872 & 849 & 835 & 13.91 & 2.46 & 61.73 & $b \mathrm{C}=\mathrm{O}(73), b \mathrm{CC}(13)$ \\
\hline 28 & - & 778 & 835 & 773 & 14.15 & 1.90 & 896.27 & $b \mathrm{CH}(63), \mathrm{CC}(23)$ \\
\hline 29 & 766 & - & 779 & 766 & 44.73 & 1.85 & 76.79 & $b \mathrm{CO}(72), b \mathrm{CC}(13)$ \\
\hline 30 & 743 & 755 & 757 & 742 & 26.37 & 1.66 & 26.39 & $b \mathrm{CH}(65), \mathrm{R}$ trigd(19) \\
\hline 31 & - & 740 & 737 & 741 & 2.51 & 1.65 & 103.72 & $b \mathrm{CC}(63), b \mathrm{CO}(17)$ \\
\hline 32 & 646 & 665 & 652 & 665 & 4.70 & 1.49 & 943.23 & Rsymd(69), Rasymd(21) \\
\hline 33 & 534 & - & 547 & 547 & 3.25 & 1.41 & 134.59 & $b C C(65)$, Rtrigd(19) \\
\hline 34 & - & 492 & 494 & 492 & 1.43 & 1.33 & 720.16 & $b \mathrm{CC}(55), w \mathrm{CC}(23)$ \\
\hline 35 & & 473 & 451 & 475 & 10.27 & 1.28 & 502.14 & $b \mathrm{CL}(60), \mathrm{R} t r i g d((19)$ \\
\hline 36 & - & 436 & 435 & 436 & 4.99 & 1.28 & 76.53 & $w \mathrm{CC}(57), t \mathrm{Rsym}(25)$ \\
\hline 37 & - & 385 & 348 & 385 & 17.64 & 1.05 & 420.70 & $w \mathrm{CC}(53), w \mathrm{CO}(29)$ \\
\hline 38 & - & 324 & 322 & 320 & 1.48 & 0.85 & 130.08 & $w \mathrm{CC}(55), t \mathrm{R}$ asym $(23)$ \\
\hline 39 & - & 270 & 281 & 270 & 2.26 & 0.68 & 47.53 & tRtrig(53), $w \mathrm{Cl}(27)$ \\
\hline 40 & - & - & 230 & 236 & 1.47 & 0.68 & 168.43 & $w \mathrm{Cl}(53), w \mathrm{CO}(23)$ \\
\hline 41 & - & 176 & 166 & 172 & 3.94 & 0.65 & 120.05 & $w \mathrm{CO}(51), w \mathrm{CC}(23)$ \\
\hline 42 & - & - & 132 & 133 & 0.20 & 0.55 & 103.96 & $\mathrm{CH}_{3}$ twist $(61)$ \\
\hline 43 & - & - & 115 & 118 & 3.88 & 0.54 & 42.39 & $t$ Rasym $(60), w \mathrm{CO}(21)$ \\
\hline 44 & - & 95 & 91 & 94 & 0.13 & 0.30 & 877.28 & $t \mathrm{Rsym}(51), t \mathrm{R} a s y m(21)$ \\
\hline 45 & - & 41 & 31 & 40 & 3.12 & 0.20 & 7.99 & $w \mathrm{CO}(52)$, tRing (19) \\
\hline
\end{tabular}

Abbreviations:- b-bending; g-out-of-plane bending; t-torsion; R-ring;; asym-assymetic; sym-symmetric; vs-very strong; s-strong; ms-medium strong; m-medium; w-weak; vw-very-weak. 
Table 3:-HOMO-LUMO energy and other related properties of methyl 2-chloronicotinate based on B3LYP/6$311++\mathrm{G}(\mathrm{d}, \mathrm{p})$ method

\begin{tabular}{|c|c|c|}
\hline \multirow[t]{2}{*}{ Parameters } & \multicolumn{2}{|c|}{ B3LYP/6-311++G(d,p) } \\
\hline & A.U & $\mathrm{eV}$ \\
\hline HOMO-3 & -0.3148 & -8.5651 \\
\hline HOMO-2 & -0.3059 & -8.3226 \\
\hline HOMO -1 & -0.2869 & -7.8064 \\
\hline HOMO & -0.2777 & -7.5558 \\
\hline LUMO & -0.0761 & -2.0700 \\
\hline LUMO+1 & -0.0540 & -1.4689 \\
\hline LUMO+2 & -0.0120 & -0.3260 \\
\hline LUMO+3 & -0.0063 & -0.1714 \\
\hline LUMO - HOMO (Energy gap) & 0.3537 & 9.6258 \\
\hline Global Hardness $(\eta)$ & -0.1008 & -2.7429 \\
\hline Electronegativity $(\chi)$ & -0.1769 & -4.8129 \\
\hline Global softness (s) & -9.9206 & -269.9544 \\
\hline Chemical potential $(\mu)$ & 0.1769 & 4.8129 \\
\hline Global Electrophilicity $(\omega)$ & -0.1552 & -4.2225 \\
\hline Dipole moment $(\mu)$ & \multicolumn{2}{|c|}{2.0696 Debye } \\
\hline Mean polarizability $(\alpha)$ & \multicolumn{2}{|c|}{$-67.8094 \times 10^{-30} \mathrm{esu}$} \\
\hline Anisotropy of the polarizability $(\Delta \alpha)$ & \multicolumn{2}{|c|}{$598.9310 \times 10^{-30} \mathrm{esu}$} \\
\hline First hyperpolarizability $(\beta)$ & \multicolumn{2}{|c|}{$1.214 \times 10^{-30} \mathrm{esu}$} \\
\hline Optimized global minimum Energy & \multicolumn{2}{|c|}{-935.9125 (Hartrees) } \\
\hline RMS & \multicolumn{2}{|c|}{0.00000628 (a.u.) } \\
\hline
\end{tabular}

Table 4:- Second order perturbation theory of fock matrix in NBO basis using B3LYP/6-311++G(d,p) basis set for 5chloro-2-hydroxypyridine

\begin{tabular}{|c|c|c|c|c|}
\hline Donor NBO $(\boldsymbol{i})$ & Acceptor NBO $(\boldsymbol{j})$ & $\boldsymbol{E}(\mathbf{2}) \boldsymbol{j} \mathbf{K} / \mathbf{m o l}$ & $\boldsymbol{E}(\boldsymbol{j})-\boldsymbol{E}(\boldsymbol{i}) \boldsymbol{a} . \boldsymbol{u}$. & $\boldsymbol{F}(\boldsymbol{i}, \boldsymbol{j}) \boldsymbol{a} . \boldsymbol{u}$. \\
\hline$\pi(\mathrm{N} 1-\mathrm{C})$ & $\pi *(\mathrm{C} 2-\mathrm{C} 17)$ & 4.36 & 0.97 & 0.058 \\
\hline$\sigma(\mathrm{N} 1-\mathrm{C} 6)$ & $\sigma *(\mathrm{C} 4-\mathrm{C} 5)$ & 12.31 & 0.32 & 0.056 \\
\hline$\sigma(\mathrm{C} 2-\mathrm{C} 3)$ & $\sigma *(\mathrm{~N} 1-\mathrm{C} 6)$ & 16.37 & 0.28 & 0.06 \\
\hline$\sigma(\mathrm{C} 2-\mathrm{C} 3)$ & $\sigma *(\mathrm{C} 4-\mathrm{C} 5)$ & 20.78 & 0.3 & 0.072 \\
\hline$\sigma(\mathrm{C} 2-\mathrm{C} 3)$ & $\sigma *(\mathrm{C} 8-\mathrm{O} 9)$ & 16.86 & 0.27 & 0.063 \\
\hline$\pi(\mathrm{C} 3-\mathrm{C} 4)$ & $\pi *(\mathrm{C} 2-\mathrm{C} 3)$ & 4.77 & 1.26 & 0.069 \\
\hline$\pi(\mathrm{C} 3-\mathrm{C} 4)$ & $\pi *(\mathrm{C} 2-\mathrm{C} 17)$ & 4.21 & 0.86 & 0.054 \\
\hline$\pi(\mathrm{C} 3-\mathrm{C} 8)$ & $\pi *(\mathrm{~N} 1-\mathrm{C} 2)$ & 3.02 & 1.16 & 0.053 \\
\hline$\pi(\mathrm{C} 4-\mathrm{C} 5)$ & $\pi *(\mathrm{C} 3-\mathrm{C} 8)$ & 3.81 & 1.07 & 0.058 \\
\hline$\sigma(\mathrm{C} 4-\mathrm{C} 5)$ & $\sigma *(\mathrm{~N} 1-\mathrm{C} 6)$ & 28.89 & 0.26 & 0.077 \\
\hline$\sigma(\mathrm{C} 4-\mathrm{C} 5)$ & $\sigma *(\mathrm{C} 2-\mathrm{C} 3)$ & 19.39 & 0.26 & 0.064 \\
\hline$\pi(\mathrm{C} 4-\mathrm{H} 15)$ & $\pi *(\mathrm{C} 2-\mathrm{C} 3)$ & 4.08 & 1.07 & 0.059 \\
\hline$\pi(\mathrm{C} 5-\mathrm{H} 16)$ & $\pi *(\mathrm{C} 3-\mathrm{C} 4)$ & 3.45 & 1.09 & 0.055 \\
\hline$\pi(\mathrm{C} 6-\mathrm{H} 17)$ & $\pi *(\mathrm{~N} 1-\mathrm{C} 2)$ & 4.49 & 1.05 & 0.062 \\
\hline$\pi(\mathrm{C} 6-\mathrm{H} 17)$ & $\pi *(\mathrm{C} 4-\mathrm{C} 5)$ & 3.37 & 1.1 & 0.055 \\
\hline$\sigma(\mathrm{C} 8-\mathrm{O} 9)$ & $\sigma *(\mathrm{C} 2-\mathrm{C} 3)$ & 4.17 & 0.37 & 0.039 \\
\hline
\end{tabular}


Table 5:- The angular properties of natural hybrid orbitals (NHO) of methyl 2-chloronicotinate using B3LYP at 6$311++\mathrm{G}(\mathrm{d}, \mathrm{p})$ basis set.

\begin{tabular}{|c|c|c|c|c|c|c|c|c|}
\hline \multirow{2}{*}{ NBO } & \multicolumn{2}{l}{ Line of Centers } & \multicolumn{2}{l|}{ Hybrid 1 } & \multicolumn{2}{l|}{ Hybrid 2 } \\
\cline { 2 - 10 } & Theta & Phi & Theta & Phi & Dev & Theta & Phi & Dev \\
\hline$\sigma(\mathrm{N} 1-\mathrm{C} 6)$ & 87.9 & 227.2 & -- & -- & -- & 92.3 & 44.5 & 2.7 \\
\hline$\pi(\mathrm{N} 1-\mathrm{C} 6)$ & 87.9 & 227.2 & 176.4 & 172.2 & 90.1 & 3.7 & 352.7 & 90 \\
\hline$\sigma(\mathrm{C} 2-\mathrm{C} 3)$ & 91.7 & 289 & 91.8 & 291.7 & 2.7 & 88.4 & 107.7 & 1.4 \\
\hline$\pi(\mathrm{C} 2-\mathrm{C} 3)$ & 91.7 & 289 & 3.9 & 352 & 89.9 & 4.2 & 352.5 & 90.2 \\
\hline$\sigma(\mathrm{C} 2-\mathrm{C} 17)$ & 92.1 & 48.9 & 92 & 50.2 & 1.3 & -- & -- & -- \\
\hline$\sigma(\mathrm{C} 3-\mathrm{C} 8)$ & 93.7 & 348.8 & 94.1 & 349.9 & 1.2 & 87.3 & 166.8 & 2.2 \\
\hline$\pi(\mathrm{C} 4-\mathrm{C} 5)$ & 86.3 & 167.3 & 176.2 & 172.2 & 89.9 & 176.3 & 172.6 & 89.9 \\
\hline$\sigma(\mathrm{C} 5-\mathrm{C} 6)$ & 88.5 & 106.6 & -- & -- & -- & 91.6 & 288.8 & 2.2 \\
\hline$\sigma(\mathrm{C} 6-\mathrm{H} 17)$ & 86.3 & 166.9 & 86.3 & 165.4 & 1.5 & -- & -- & -- \\
\hline$\sigma(\mathrm{C} 8-\mathrm{O} 9)$ & 91.7 & 288.7 & 92.1 & 290.5 & 1.8 & -- & -- & -- \\
\hline$\pi(\mathrm{C} 8-\mathrm{O} 9)$ & 91.7 & 288.7 & 3.7 & 341.5 & 89.4 & 177.1 & 183.2 & 90.9 \\
\hline$\sigma(\mathrm{C} 8-\mathrm{O} 10)$ & 92.1 & 48.8 & 90.9 & 45.2 & 3.8 & 87.4 & 227.6 & 1.4 \\
\hline$\sigma(\mathrm{O} 10-\mathrm{C} 11)$ & 65.5 & 341.3 & 64.4 & 341.2 & 1.1 & 114.1 & 163.7 & 2.2 \\
\hline$\sigma(\mathrm{C} 11-\mathrm{H} 12)$ & 120.2 & 294.8 & 121.6 & 293.8 & 1.7 & -- & -- & -- \\
\hline$\sigma(\mathrm{C} 11-\mathrm{H} 13)$ & 92.1 & 48.8 & 92.8 & 51 & 2.3 & -- & -- & -- \\
\hline$\sigma(\mathrm{C} 11-\mathrm{H} 14)$ & 17.7 & 238.5 & 18.5 & 231.1 & 2.5 & -- & -- & -- \\
\hline$\pi^{*}(\mathrm{~N} 1-\mathrm{C} 6)$ & 87.9 & 227.2 & 176.4 & 172.2 & 90.1 & 3.7 & 352.7 & 90 \\
\hline$\pi^{*}(\mathrm{C} 2-\mathrm{C} 3)$ & 91.7 & 289 & 3.9 & 352 & 89.9 & 4.2 & 352.5 & 90.2 \\
\hline$\pi^{*}(\mathrm{C} 4-\mathrm{C} 5)$ & 86.3 & 167.3 & 176.2 & 172.2 & 89.9 & 176.3 & 172.6 & 89.9 \\
\hline$\pi^{*}(\mathrm{C} 8-\mathrm{O} 9)$ & 91.7 & 288.7 & 3.7 & 341.5 & 89.4 & 177.1 & 183.2 & 90.9 \\
\hline$\sigma^{*}(\mathrm{C} 8-\mathrm{O} 10)$ & 92.1 & 48.8 & 90.9 & 45.2 & 3.8 & 87.4 & 227.6 & 1.4 \\
\hline
\end{tabular}

Table 6:- Temperature dependence of the thermodynamic properties of methyl 2-chloronicotinate determined by DFT/B3LYP 6-311++G(d,p) method.

\begin{tabular}{|c|c|c|c|}
\hline \multirow{2}{*}{$\mathrm{T}(\mathrm{K})$} & \multicolumn{3}{|c|}{ methyl 2-chloronicotinate } \\
\cline { 2 - 4 } & $\begin{array}{c}\mathrm{S} \\
\left(\mathrm{J}^{-1} \mathrm{~mol}^{-1} \cdot \mathrm{K}^{-1}\right)\end{array}$ & $\begin{array}{c}\mathrm{Cp} \\
\left(\mathrm{J} \cdot \mathrm{mol}^{-1} \cdot \mathrm{K}^{-1}\right)\end{array}$ & $\begin{array}{c}\Delta \mathrm{H}_{0} \rightarrow \mathrm{T} \\
\left(\mathrm{kJ}^{\left.-\mathrm{mol}^{-1}\right)}\right.\end{array}$ \\
\hline 100 & 72.04588906 & 18.61615678 & 1.3026 \\
\hline 200 & 87.92065004 & 28.14053536 & 3.6472 \\
\hline 298.15 & 100.8867112 & 37.45697895 & 6.8642 \\
\hline 300 & 101.1185468 & 37.63145313 & 6.9336 \\
\hline 400 & 113.2146271 & 46.73757167 & 16.1616 \\
\hline 500 & 124.5124282 & 54.56261947 & 22.0244 \\
\hline 600 & 135.045411 & 60.94168257 & 28.3843 \\
\hline 700 & 144.8398661 & 66.09464623 & 35.2127 \\
\hline 800 & 153.9483747 & 70.29397701 & 42.4187 \\
\hline 900 & 162.4354684 & 73.75717013 & 49.9450 \\
\hline 1000 & 170.3585085 & 76.64674948 & \\
\hline
\end{tabular}


Table 7:- Theoretically computed zero point vibrational energy $\left(\mathrm{kcal} \mathrm{mol}^{-1}\right)$, rotational constant $(\mathrm{GHz})$, rotational temperature (kelvin), thermal energy $\left(\mathrm{kcal} \mathrm{mol}^{-1}\right)$, molar capacity at constant volume $\left(\mathrm{cal} \mathrm{mol}^{-1} \mathrm{kelvin}^{-1}\right)$, entropy (cal $\mathrm{mol}^{-1} \mathrm{kelvin}^{-1}$ ), vibrational temperature (kelvin) of methyl 2-chloronicotinateby B3LYP/6-311++G(d,p) method.

\begin{tabular}{|c|c|}
\hline Parameter & B3LYP/6-311++G(d,p) \\
\hline Zero point vibrational energy & 75.99076 \\
\hline Rotational constant & 1.46582 \\
\hline & 0.81413 \\
\hline & 0.54415 \\
\hline Rotational temperatures & 0.07035 \\
\hline & 0.03907 \\
\hline & 0.02612 \\
\hline Energy & \\
\hline Total & 82.263 \\
\hline Translation & 0.889 \\
\hline Rotational & 0.889 \\
\hline Vibrational & 80.485 \\
\hline Molar capacity at constant vol & \\
\hline Total & 35.469 \\
\hline Translational & 2.981 \\
\hline Rotational & 2.981 \\
\hline Vibrational & 29.508 \\
\hline Entropy & \\
\hline Total & 100.860 \\
\hline Translational & 41.317 \\
\hline Rotational & 30.583 \\
\hline Vibrational & 28.960 \\
\hline
\end{tabular}

Table 8:- NMR -Chemical Shielding Anisotropy parameters of methyl 2-chloronicotinatebased on B3LYP/6$311++\mathrm{G}(\mathrm{d}, \mathrm{p})$

method.

\begin{tabular}{|c|c|c|c|c|c|c|c|c|c|c|c|}
\hline Atom & $\sigma 1(\mathrm{ppm})$ & $\sigma 2(\mathrm{ppm})$ & $\sigma 3(\mathrm{ppm})$ & $\begin{array}{c}\sigma_{\text {iso }} \\
(\mathbf{p p m})\end{array}$ & $\begin{array}{c}\sigma_{\text {aniso }} \\
(\mathbf{p p m})\end{array}$ & $\eta$ & $\mathbf{\Omega}(\mathbf{p p m})$ & $\mathbf{k}$ & $\rho($ ppm) & $\operatorname{mode}(\sigma)$ & $\tau(\mathrm{rad})$ \\
\hline \multicolumn{12}{|l|}{$\mathrm{C}^{13}$} \\
\hline $\mathrm{C} 2$ & -74.2355 & 21.2688 & 83.3609 & 10.1314 & 109.8443 & 1.3042 & 157.5964 & 0.2120 & 137.5011 & -0.3573 & -0.1218 \\
\hline $\mathrm{C} 3$ & -34.3375 & 42.8281 & 140.5838 & 49.6915 & 136.3385 & 0.8490 & 174.9213 & -0.1177 & 151.8357 & 0.2022 & 0.0679 \\
\hline $\mathrm{C} 4$ & -68.6534 & 12.6634 & 175.7384 & 39.9161 & 203.7334 & 0.5987 & 244.3918 & -0.3345 & 215.5612 & 0.5416 & \begin{tabular}{|l|}
0.1908 \\
\end{tabular} \\
\hline $\mathrm{C} 5$ & -58.9559 & 47.7238 & \begin{tabular}{|l|}
172.2178 \\
\end{tabular} & 53.6619 & 177.8339 & 0.8998 & 231.1737 & -0.0771 & 200.4003 & 0.1330 & \begin{tabular}{|l|}
0.0445 \\
\end{tabular} \\
\hline C6 & $\begin{array}{l}-92.0904 \\
\end{array}$ & 24.1 & & 23.0596 & 171.2748 & 1.0169 & 229 & 0.0126 & 137 & -0.0219 & -0.0073 \\
\hline $\mathrm{C} 8$ & -122.2801 & 29.7131 & 46.7 & -15.2719 & 93.0348 & 2.4506 & 169.0314 & 0.7984 & 161.1891 & -0.9624 & -0.4319 \\
\hline C11 & 102.5479 & 111.6423 & 182.0077 & 132.0660 & 74.9126 & 0.1821 & 79.4598 & -0.7711 & 75.3255 & 0.9510 & 0.4188 \\
\hline \multicolumn{12}{|l|}{$\mathrm{H}^{1}$} \\
\hline H12 & 23.5114 & 26.5953 & 32.6199 & 27.5755 & 7.5666 & 0.6114 & 9.1085 & -0.3229 & 8.0241 & 0.5251 & \begin{tabular}{|l|}
0.1843 \\
\end{tabular} \\
\hline H13 & 25.35 & 27.2687 & 33.5624 & 28.7270 & 7.2530 & 0.3968 & 8.2124 & -0.5327 & 7.4410 & 0.7803 & \begin{tabular}{|l|}
0.2984 \\
\end{tabular} \\
\hline H14 & & & & 29.29 & 9.2359 & 0.2867 & 85 & -0.6511 & & 0.8813 & \begin{tabular}{|l|}
0.3596 \\
\end{tabular} \\
\hline H15 & 19.8949 & 22.2636 & 28. & 23.5081 & 7.2865 & 0.4876 & 8.4 & -0.4407 & 5697 & 0.6798 & 0.2492 \\
\hline H16 & 22.4316 & 23.5586 & 28.4813 & 24.8238 & 5.4862 & 0.3081 & 6.0497 & -0.6274 & 5.5723 & 0.8637 & \begin{tabular}{|l|}
0.3475 \\
\end{tabular} \\
\hline H17 & 19.9554 & 21.8196 & 27.3769 & 23.0506 & 6.4894 & 0.4309 & 7.4215 & -0.4976 & 6.6872 & 0.7442 & \begin{tabular}{|l|}
0.2798 \\
\end{tabular} \\
\hline
\end{tabular}

$\sigma 1, \sigma 2, \sigma 3$ - Eigen values of the symmetrized shielding tensor $\eta$ - asymmetry $\Omega$-span k- skew

$\sigma_{\text {iso }}$ - isotropic shielding tensor

бaniso - Shielding Anisotropy $\rho$ - magnitude of anisotropy $\tau$ - orientation if anisotropy 
Table 9:- Magnetic susceptibility of methyl 2-chloronicotinate by B3LYP/6-311++G (d, p).

\begin{tabular}{|c|c|c|c|}
\hline Temperature & Magnetic susceptibility & 1/Susceptibility & 1/Temperature \\
\hline 50 & $1.01752 \mathrm{E}-06$ & 982779.7335 & 0.02 \\
\hline 100 & $5.08761 \mathrm{E}-07$ & 1965559.467 & 0.01 \\
\hline 150 & $3.39174 \mathrm{E}-07$ & 2948339.201 & 0.006667 \\
\hline 200 & $2.54381 \mathrm{E}-07$ & 3931118.934 & 0.005 \\
\hline 250 & $2.03504 \mathrm{E}-07$ & 4913898.668 & 0.004 \\
\hline 273 & $1.86359 \mathrm{E}-07$ & 5365977.345 & 0.003663 \\
\hline 298.15 & $1.70639 \mathrm{E}-07$ & 5860315.551 & 0.003354 \\
\hline 300 & $1.69587 \mathrm{E}-07$ & 5896678.401 & 0.003333 \\
\hline 350 & $1.4536 \mathrm{E}-07$ & 6879458.135 & 0.002857 \\
\hline 400 & $1.2719 \mathrm{E}-07$ & 7862237.868 & 0.0025 \\
\hline 450 & $1.13058 \mathrm{E}-07$ & 8845017.602 & 0.002222 \\
\hline 500 & $1.01752 \mathrm{E}-07$ & 9827797.335 & 0.002 \\
\hline
\end{tabular}

Table 10:-Natural atomic charge distribution of methyl 2-chloronicotinatebased on B3LYP/6-311++G(d,p) methods.

\begin{tabular}{|c|c|c|}
\hline \multirow{2}{*}{ Atoms } & \multicolumn{2}{|c|}{ Atomic Charges } \\
\cline { 2 - 3 } & Mulliken & -0.46282 \\
\hline N1 & 0.14475 & 0.22305 \\
\hline C2 & -1.353087 & -0.20511 \\
\hline C3 & 1.458359 & -0.1159 \\
\hline C4 & -0.16791 & -0.23396 \\
\hline C5 & -0.105227 & 0.08875 \\
\hline C6 & -0.180639 & 0.06527 \\
\hline C17 & 0.464069 & 0.80572 \\
\hline C8 & -0.854993 & -0.59637 \\
\hline O9 & -0.236987 & -0.55945 \\
\hline O10 & -0.046049 & -0.20508 \\
\hline C11 & -0.267399 & 0.19064 \\
\hline H12 & 0.190207 & 0.18452 \\
\hline H14 & 0.158669 & 0.17186 \\
\hline H15 & 0.178544 & 0.23849 \\
\hline H16 & 0.211491 & 0.21458 \\
\hline H17 & 0.195114 & 0.19581 \\
\hline
\end{tabular}




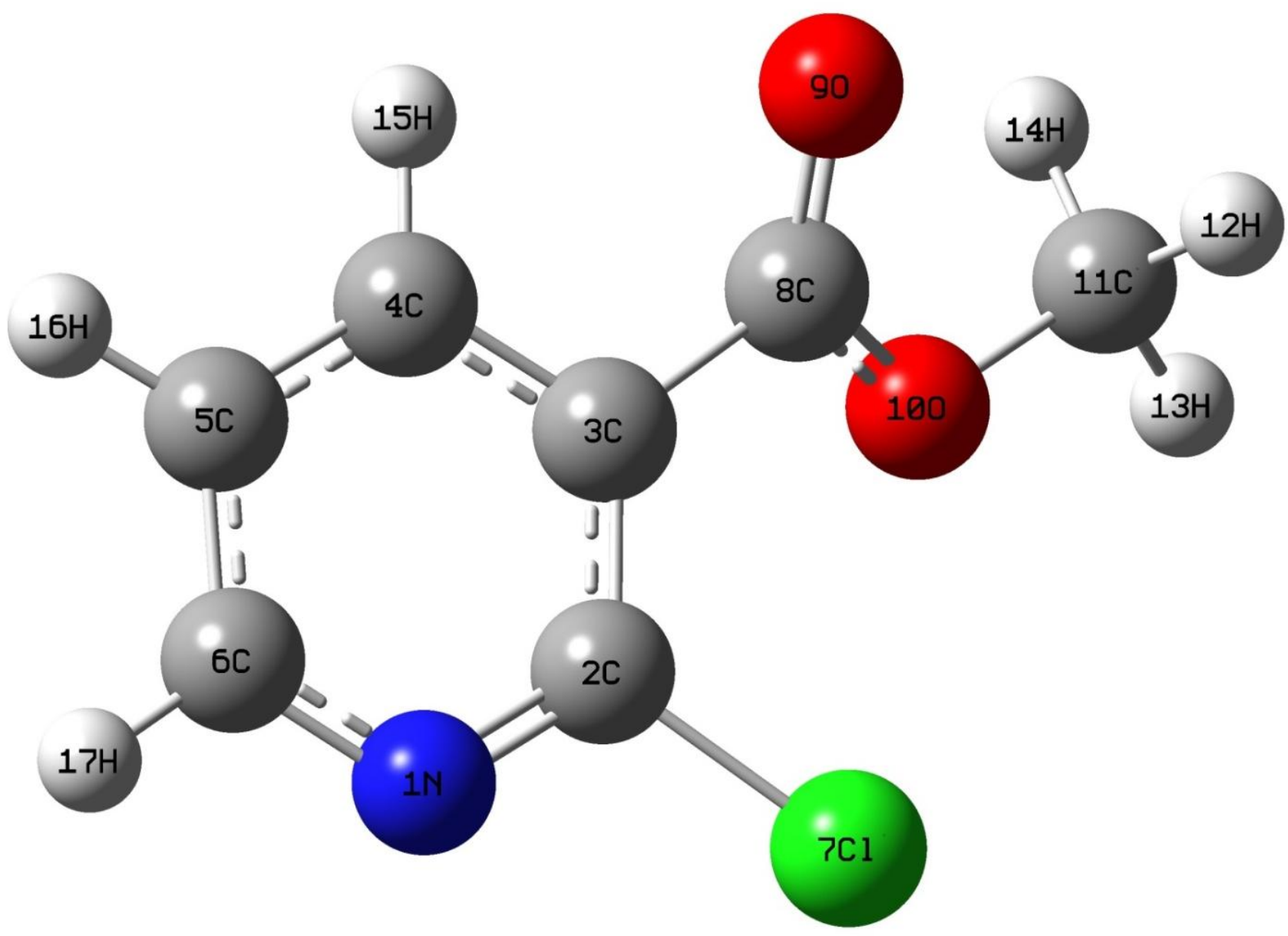

Fig. 1. Optimized molecular structure of methyl-2-chloronicotinate.

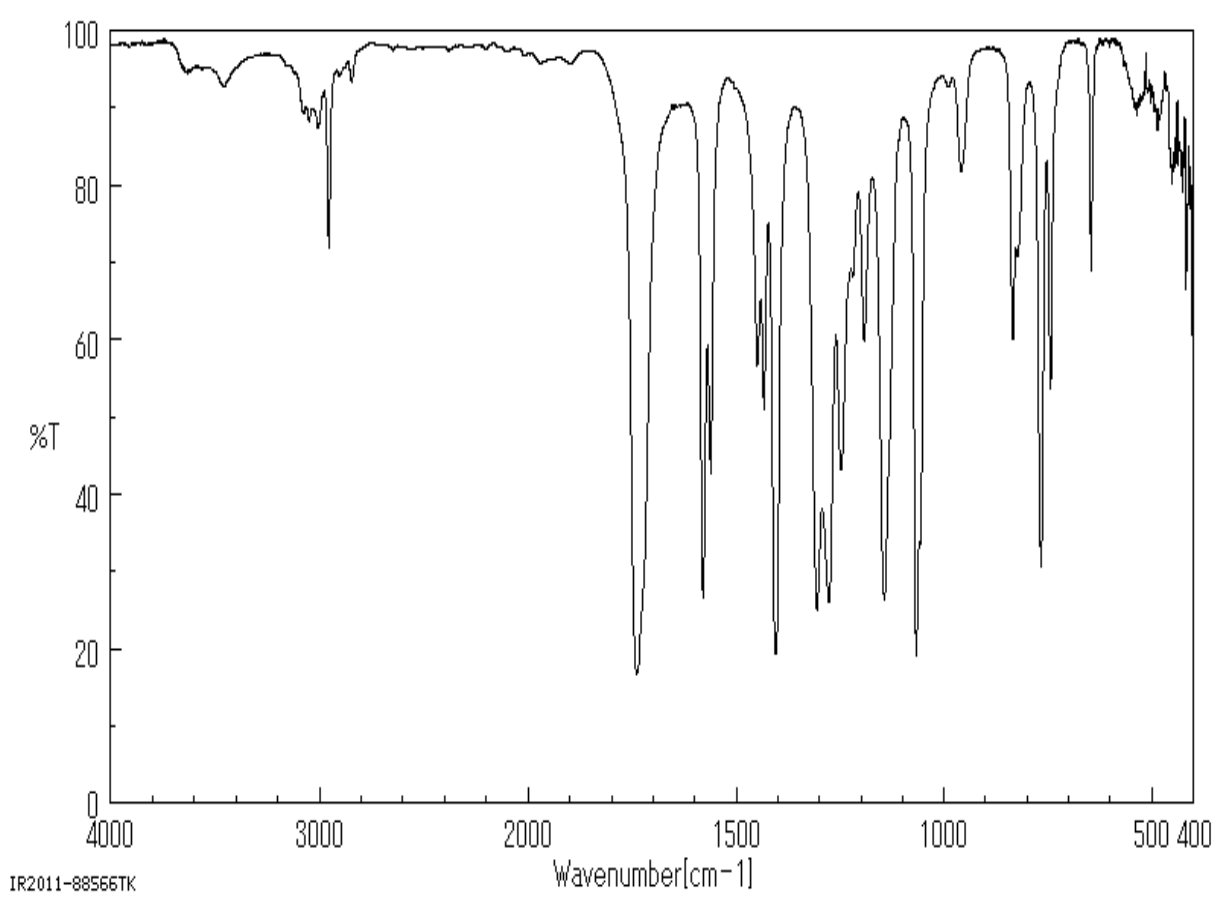

Fig. 2:- FT-IR spectrum of methyl-2-chloronicotinate. 


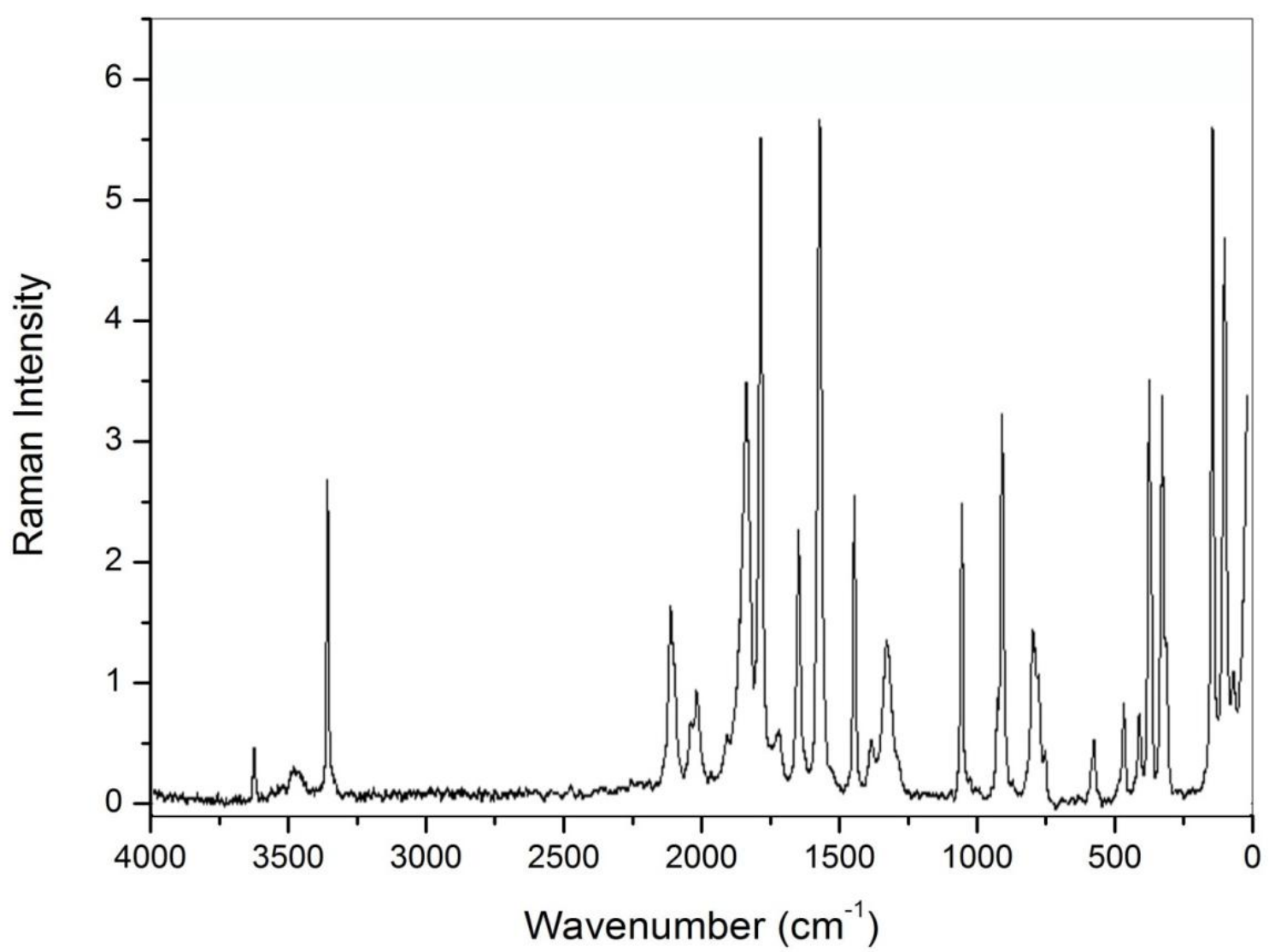

Fig 3:- FT-Raman spectrum of methyl-2-chloronicotinate. 


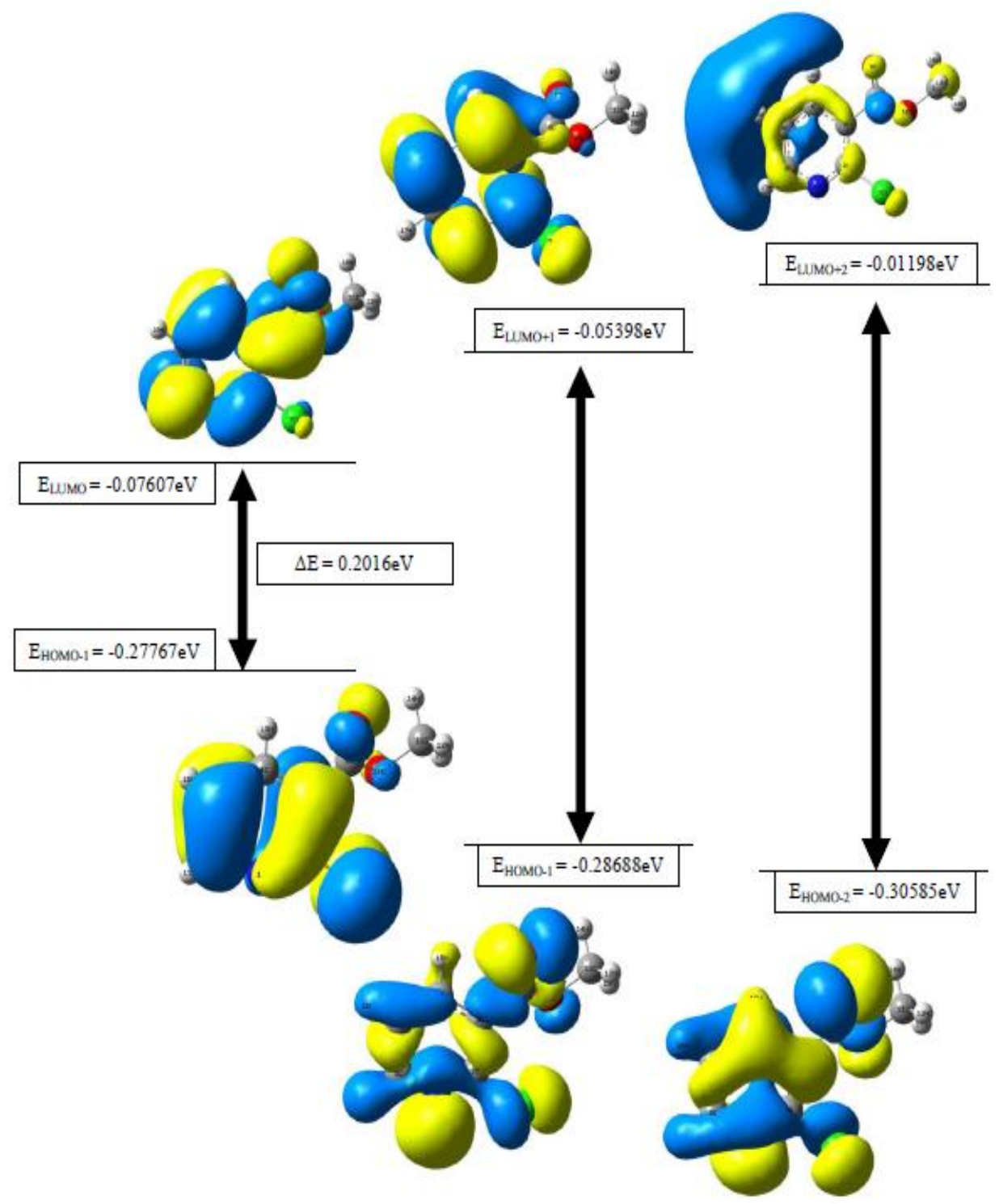

Fig. 4:- The atomic orbital compositions of the Frontier Molecular Orbitals for methyl-2-chloronicotinate. 


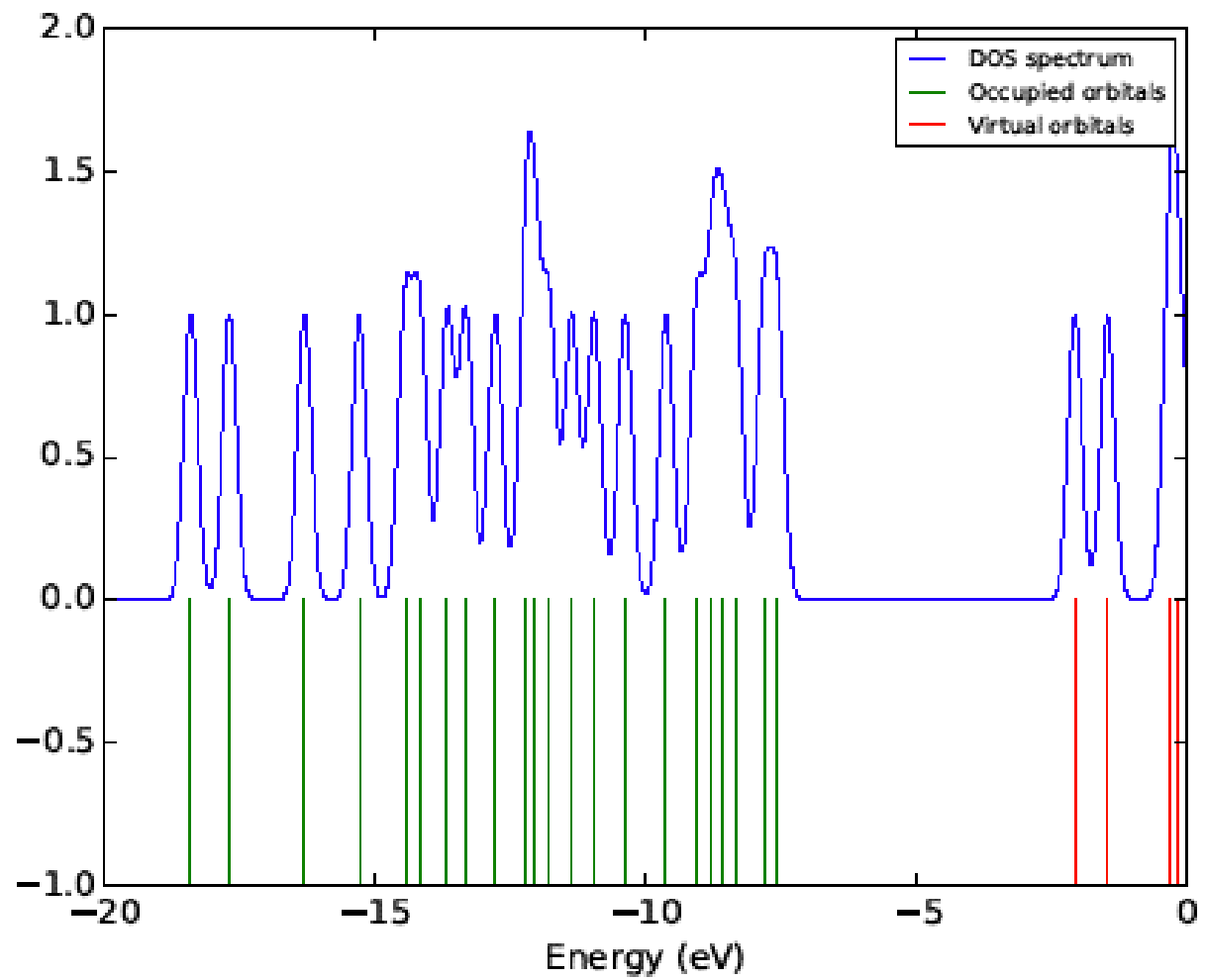

Fig. 5:- Density ofStates (DOS) diagram for methyl-2-chloronicotinate.

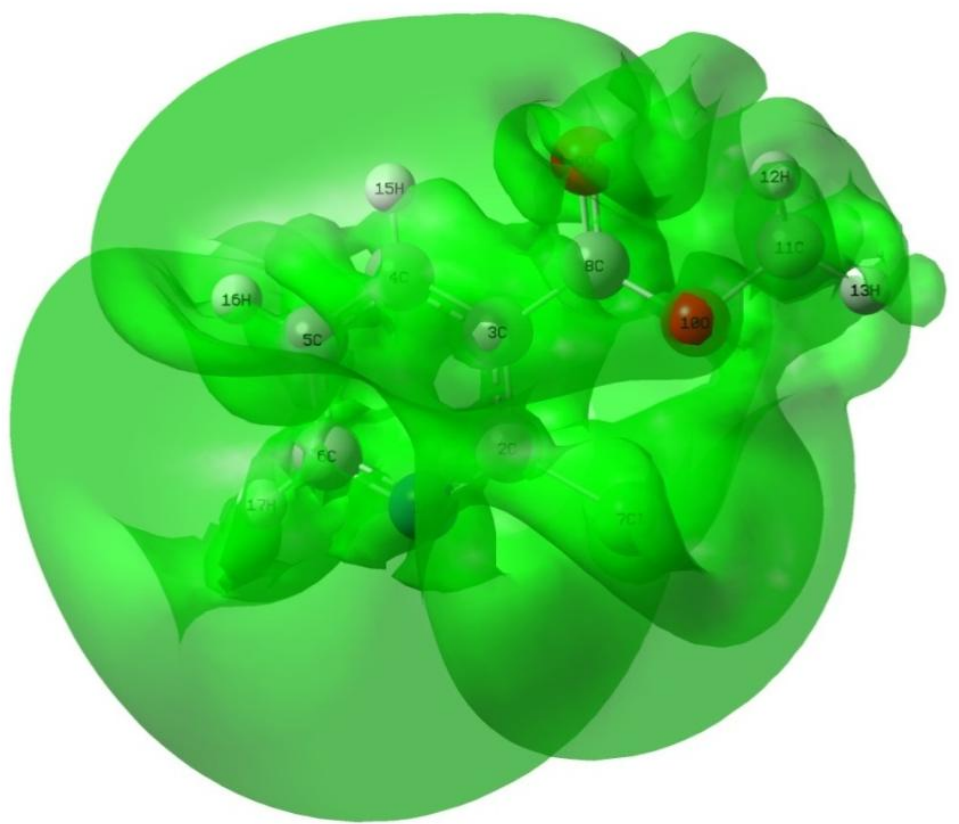

Fig 6:- Electron density spin magnitude density contours for methyl-2-chloronicotinate. 


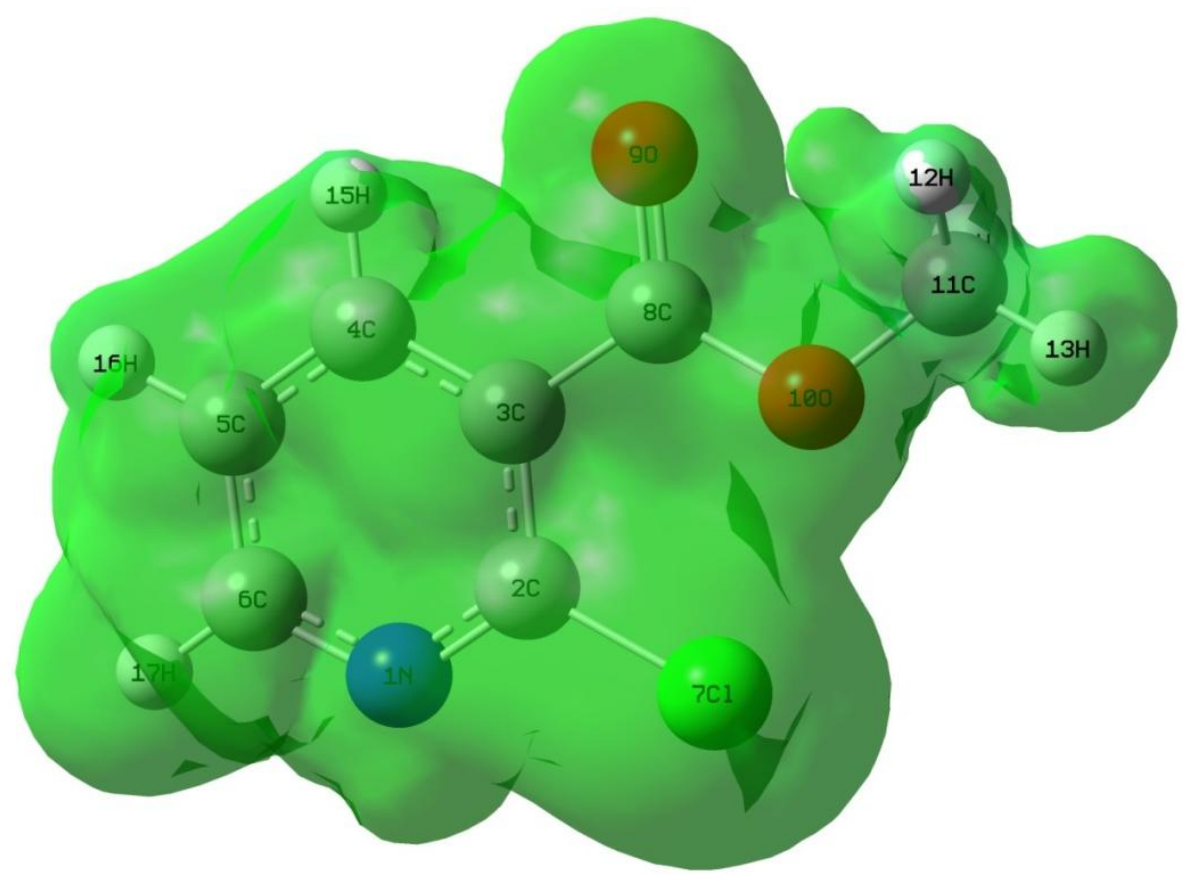

Fig 7:- Electron density form magnitude of magnetically induced current density for methyl-2-chloronicotinate.

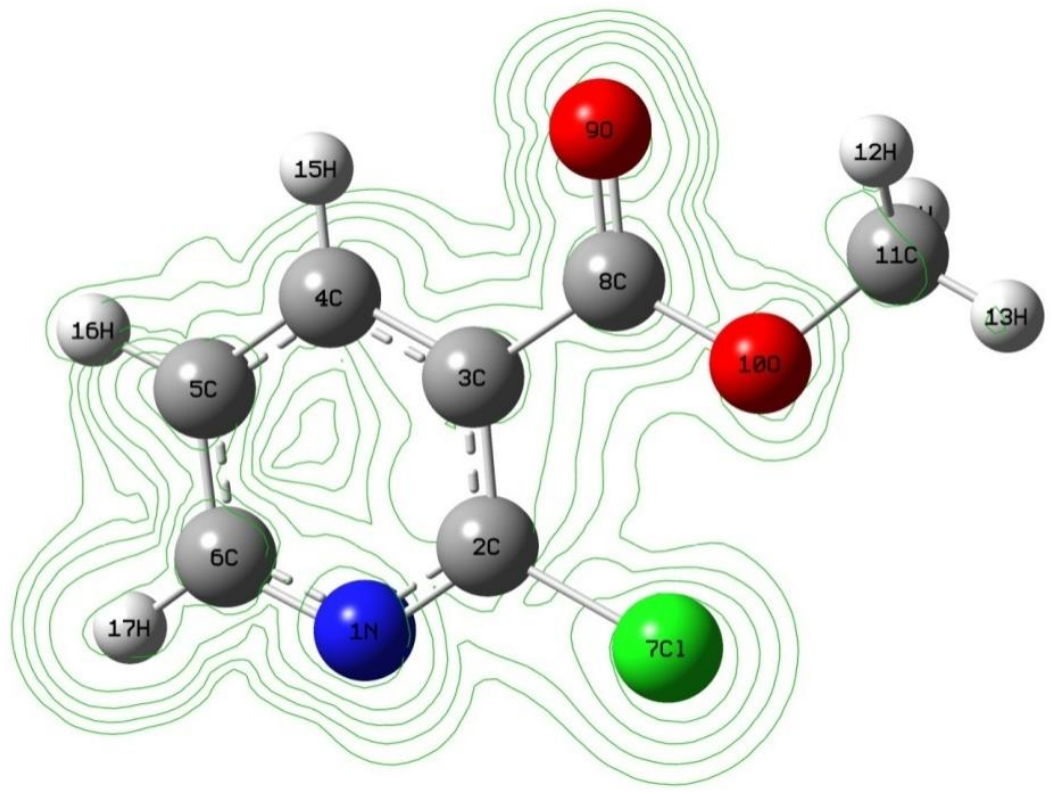

Fig 8:- Electron density form magnitude of magnetically induced current density contoursfor methyl-2chloronicotinate. 


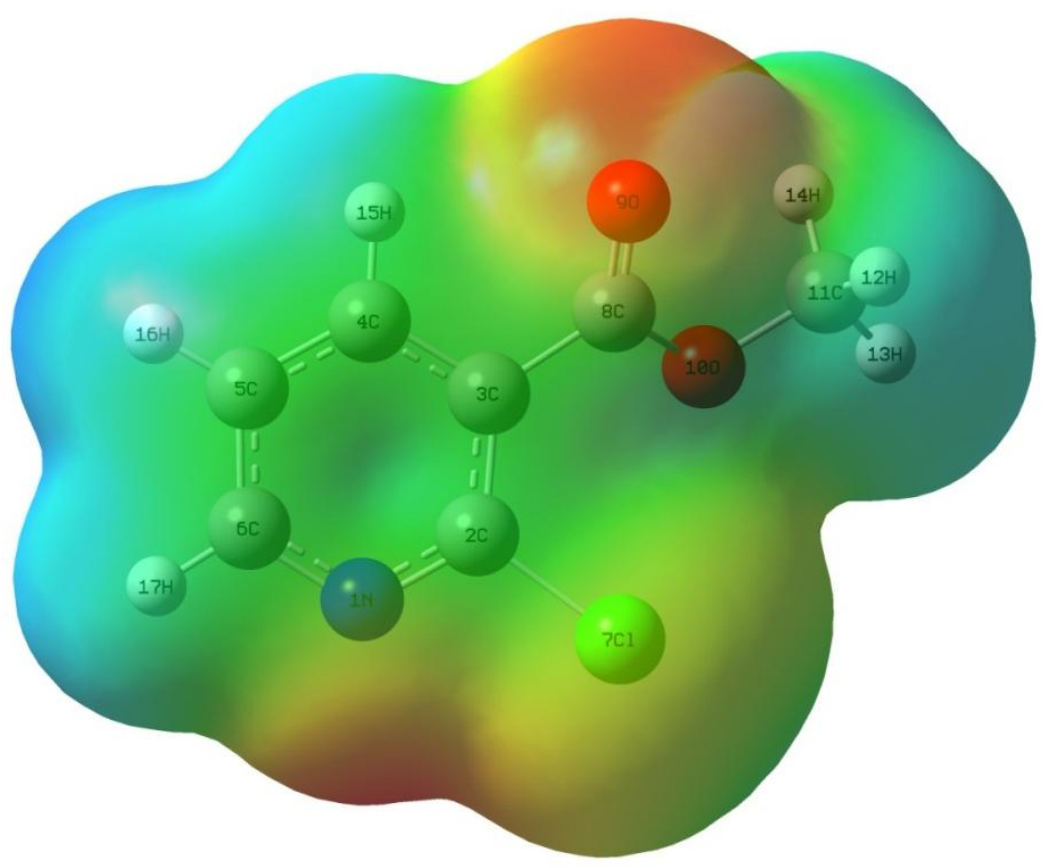

Fig 9:- Molecular electrostatic potential for methyl-2-chloronicotinate.

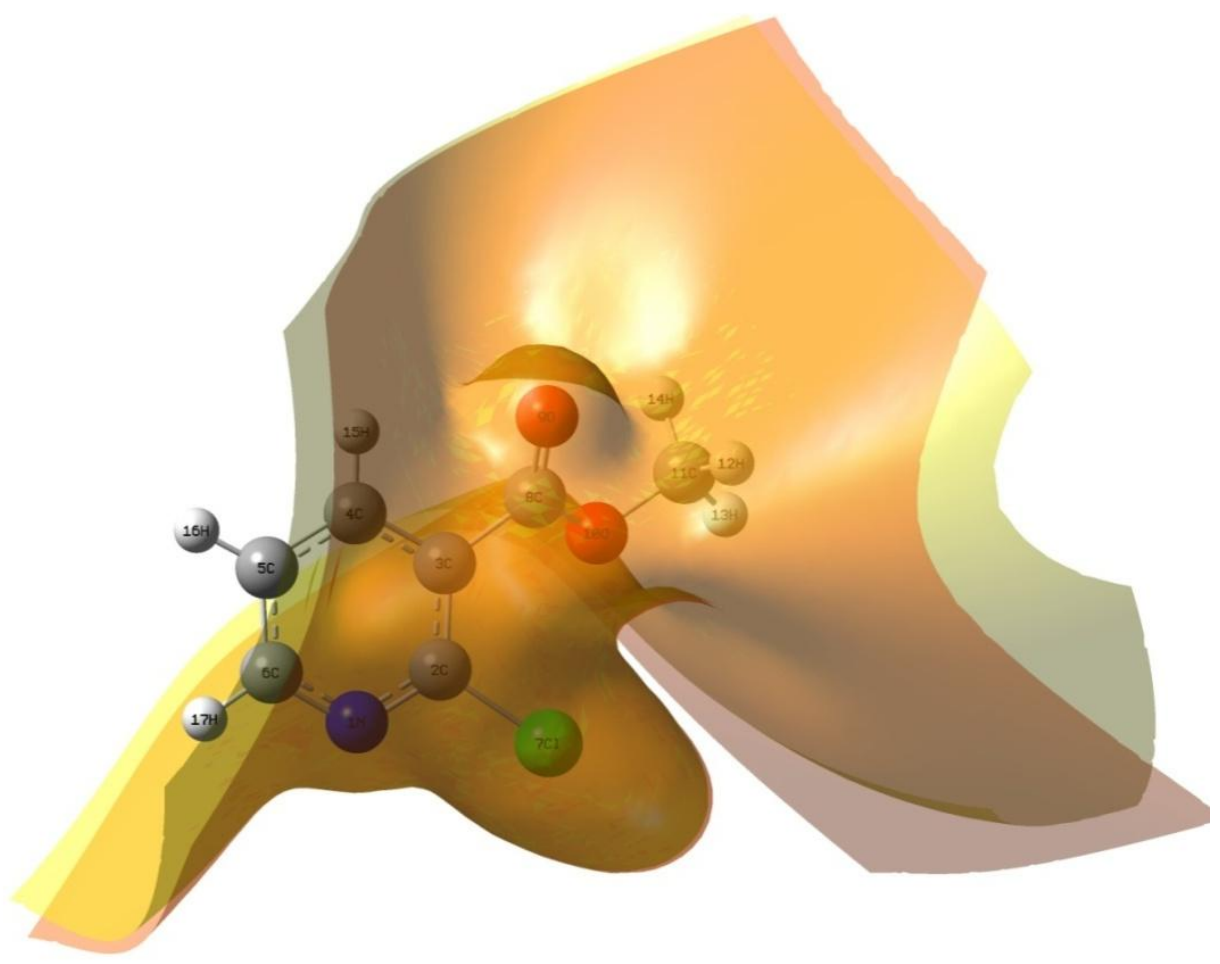

Fig 10:- Electrostatic potential surface for methyl-2-chloronicotinate. 


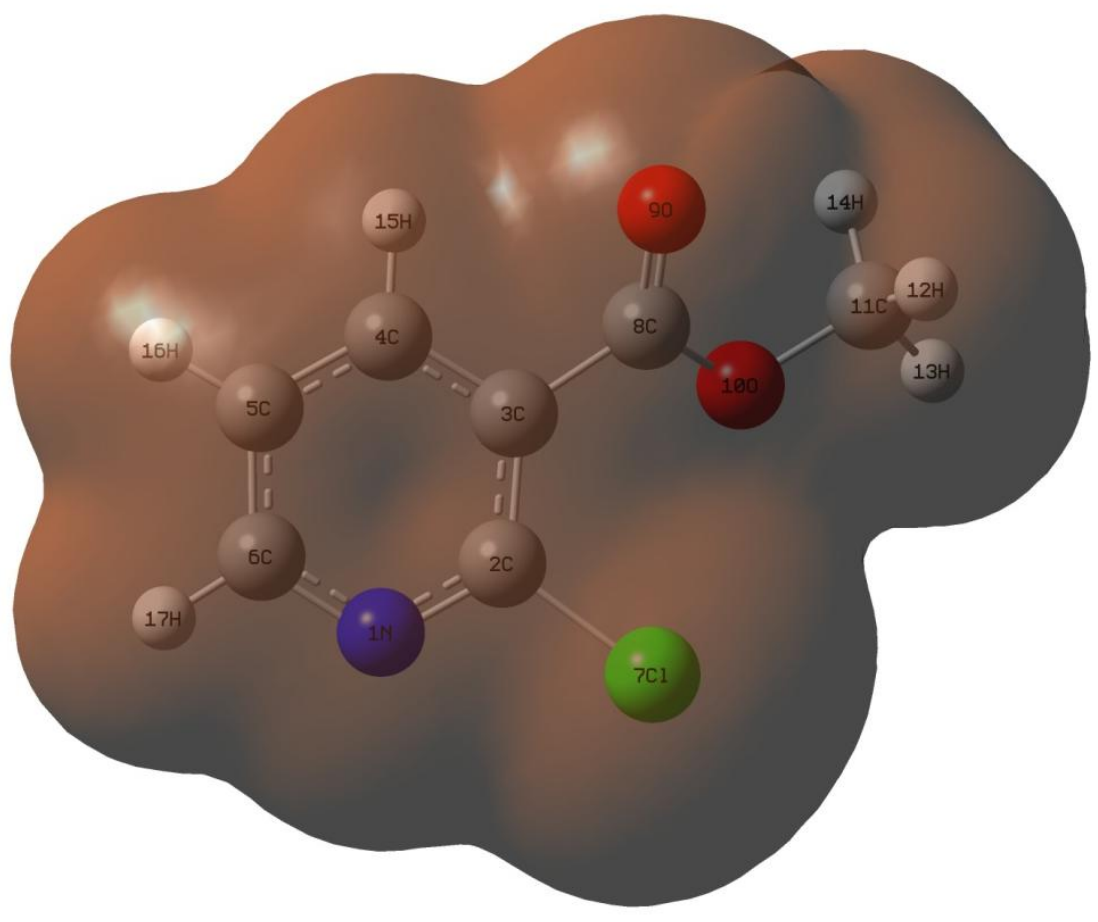

Fig 11:-The total alpha density surface for methyl-2-chloronicotinate.

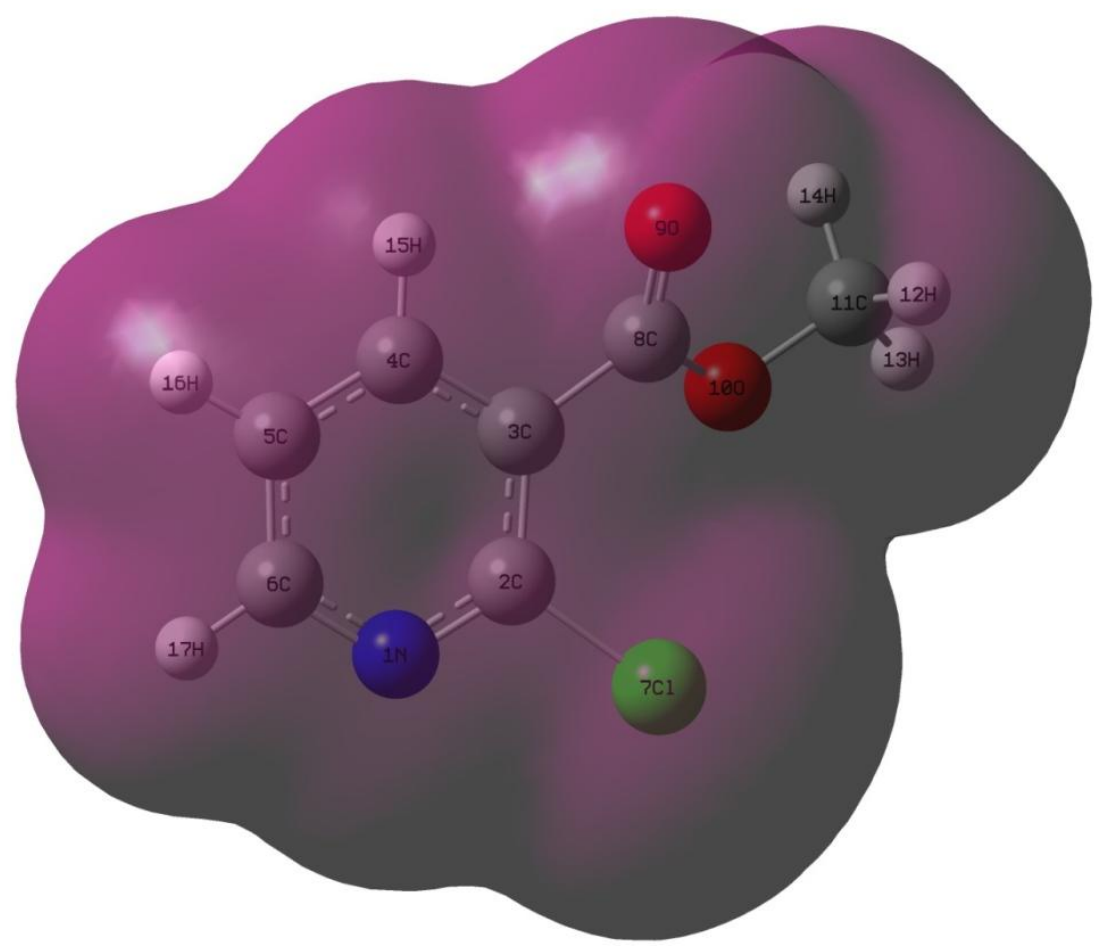

Fig 12:-The total electron density surface for methyl-2-chloronicotinate. 


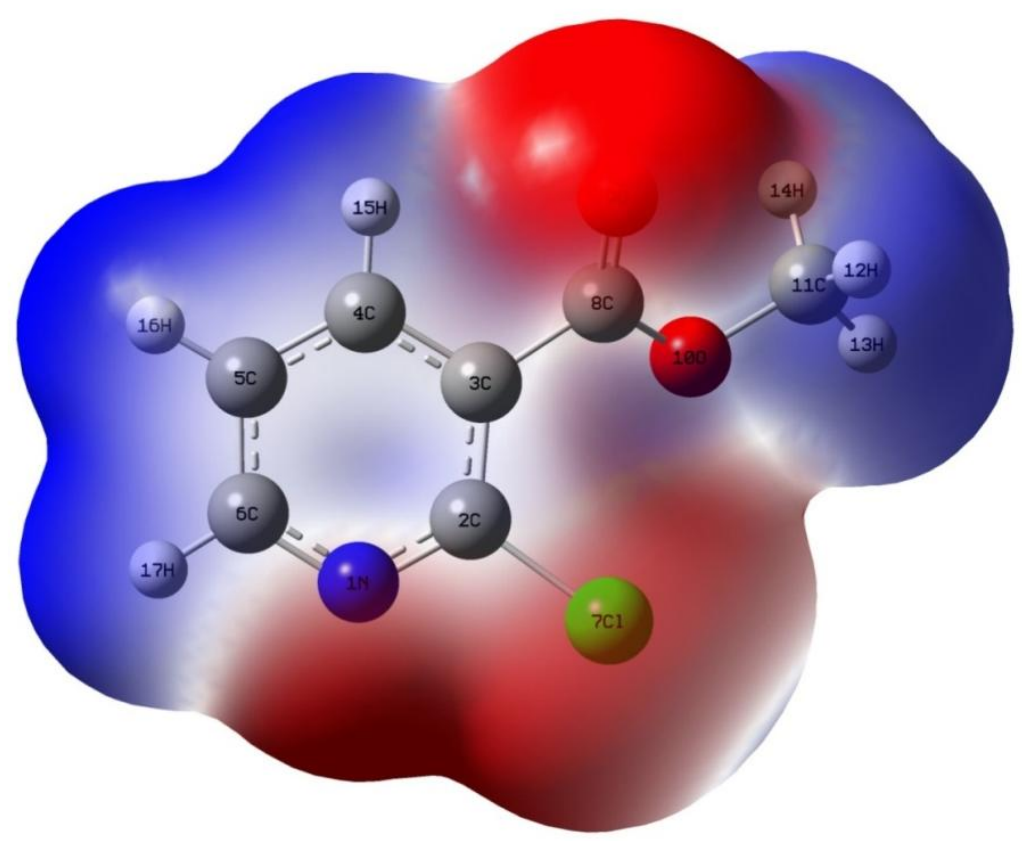

Fig 13:- The total alpha density surface for methyl-2-chloronicotinate.

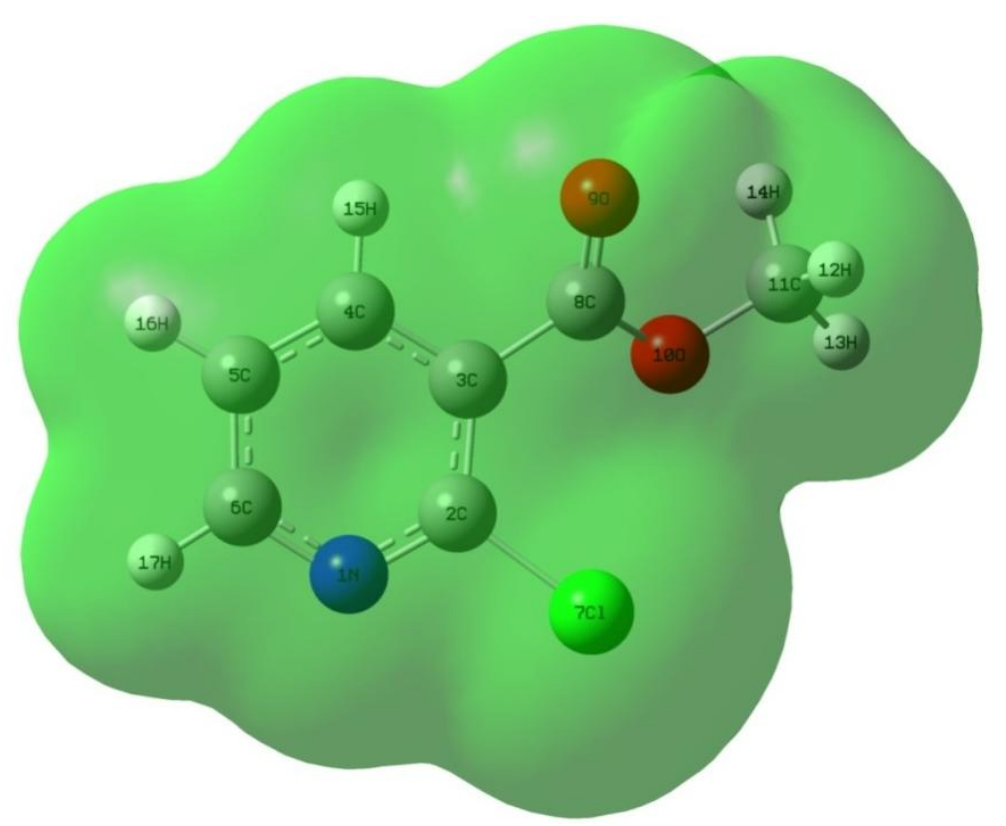

Fig 14:- Electrostatic potential isoval surface for methyl-2-chloronicotinate. 


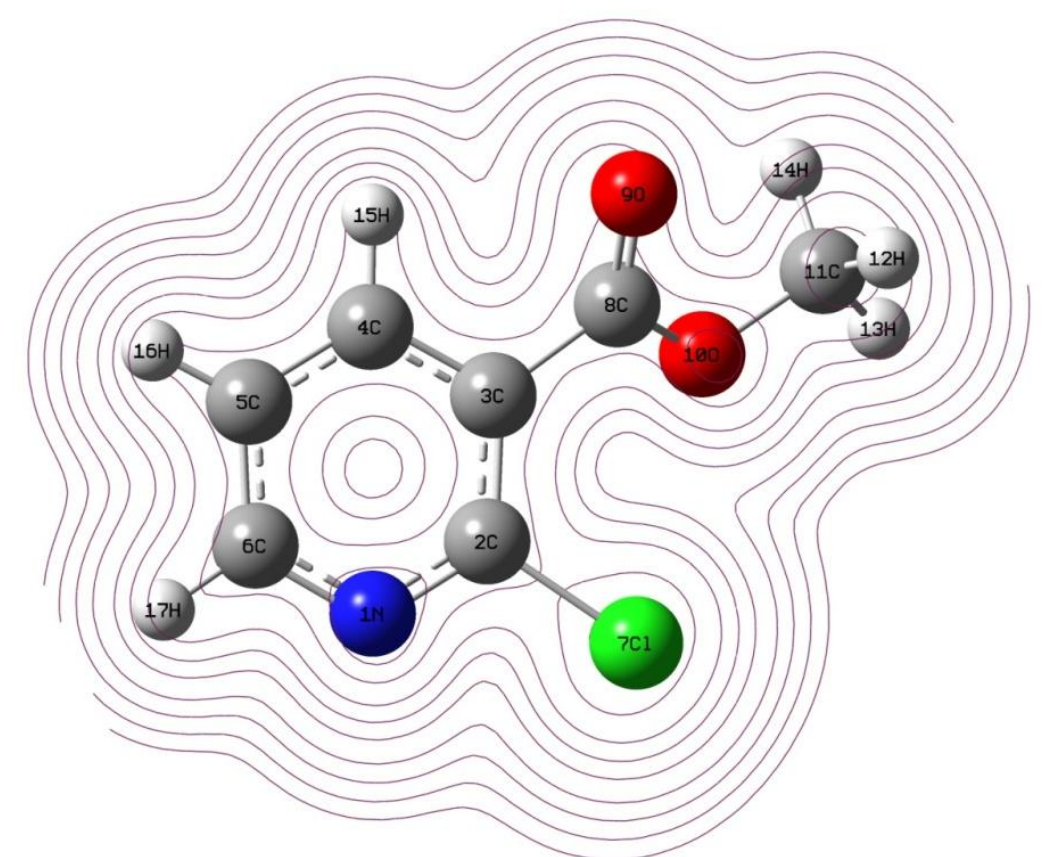

Fig 15:- Electron density contour surface for methyl-2-chloronicotinate.

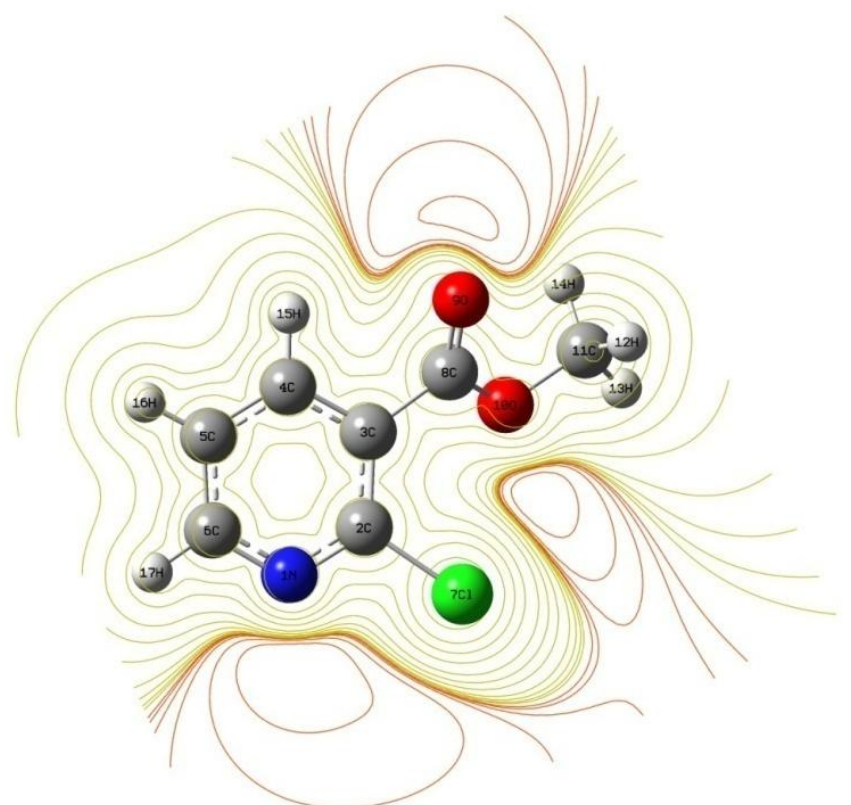

Fig 16:- Electrostatic Potential MEP for methyl-2-chloronicotinate. 


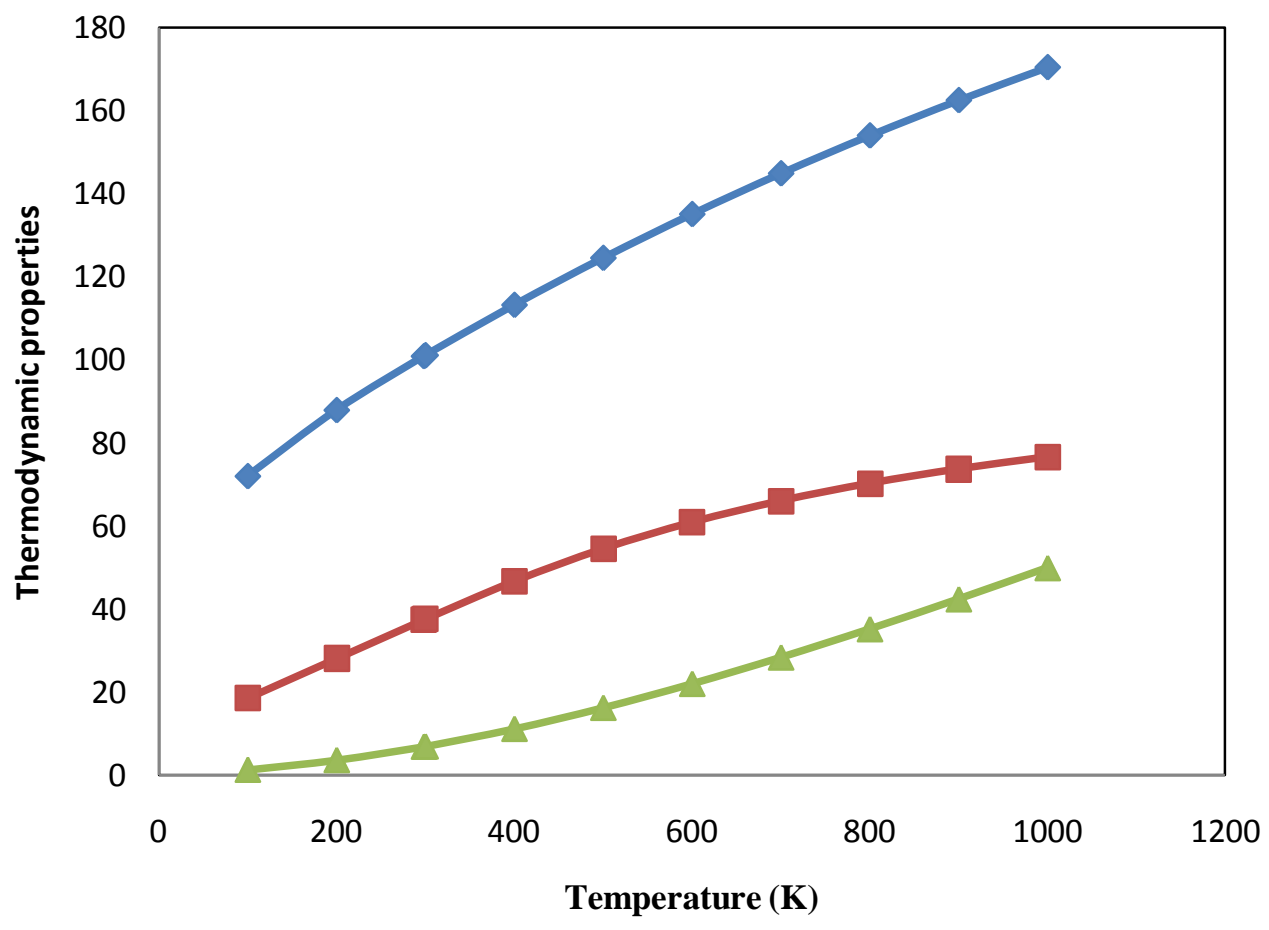

$\leadsto \mathrm{S}(\mathrm{J} . \mathrm{mol}-1 . \mathrm{K}-1) \quad \longrightarrow \mathrm{Cp}(\mathrm{J} . \mathrm{mol}-1 . \mathrm{K}-1) \quad \triangle \mathrm{HO} \rightarrow \mathrm{T}(\mathrm{kJ} . \mathrm{mol}-1)$

Fig 17:- Correlation graph of thermodynamic parameters for methyl-2-chloronicotinate.

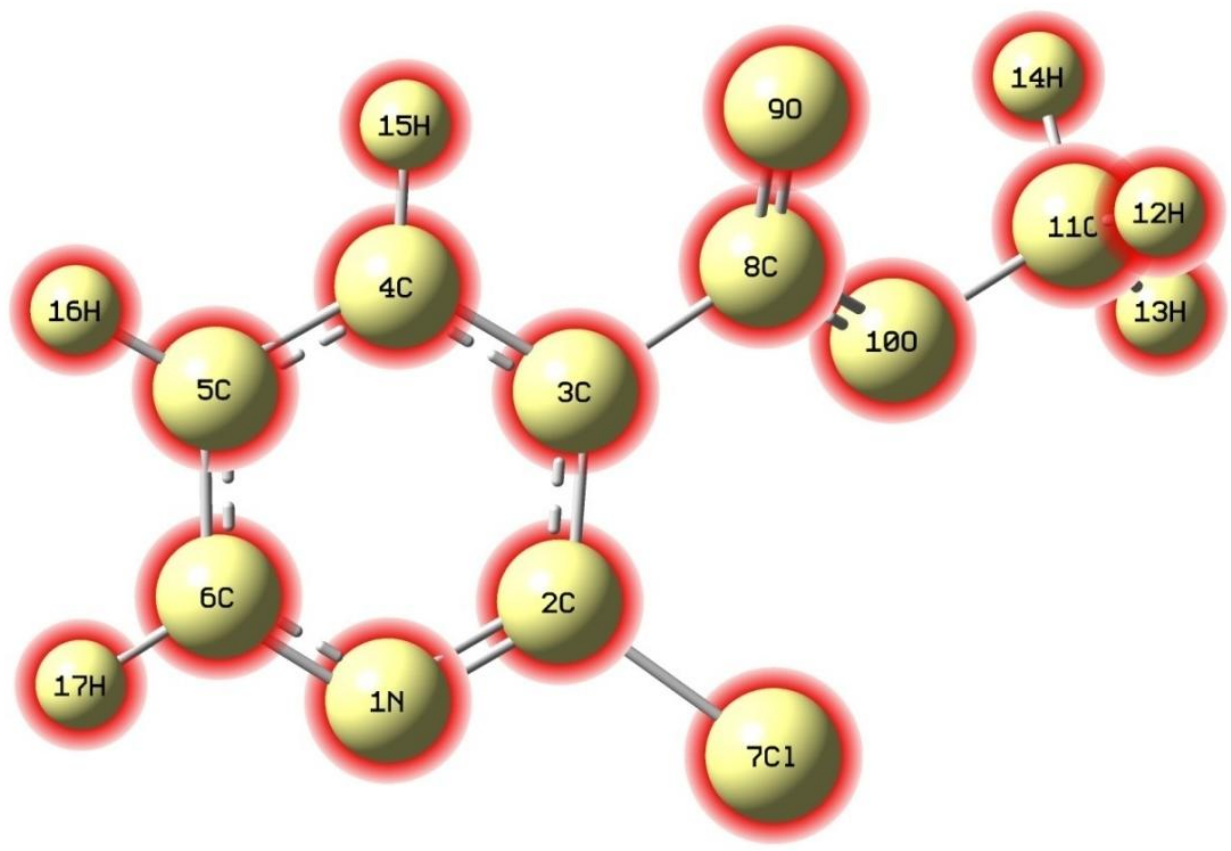

Fig 18:- The NMR Spin-Spin shieldingsurfacesfor methyl-2-chloronicotinate. 


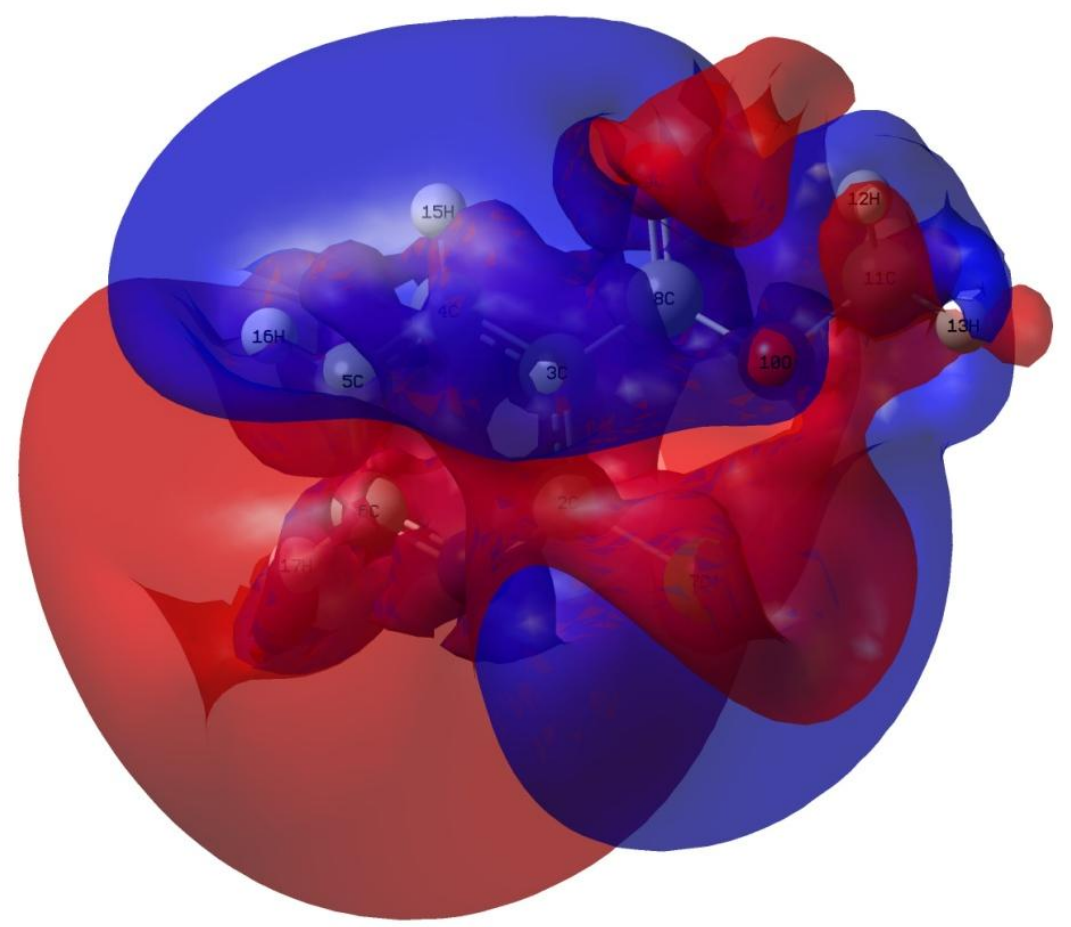

Fig 19:- The NMR shieldingsurfacesfor methyl-2-chloronicotinate.

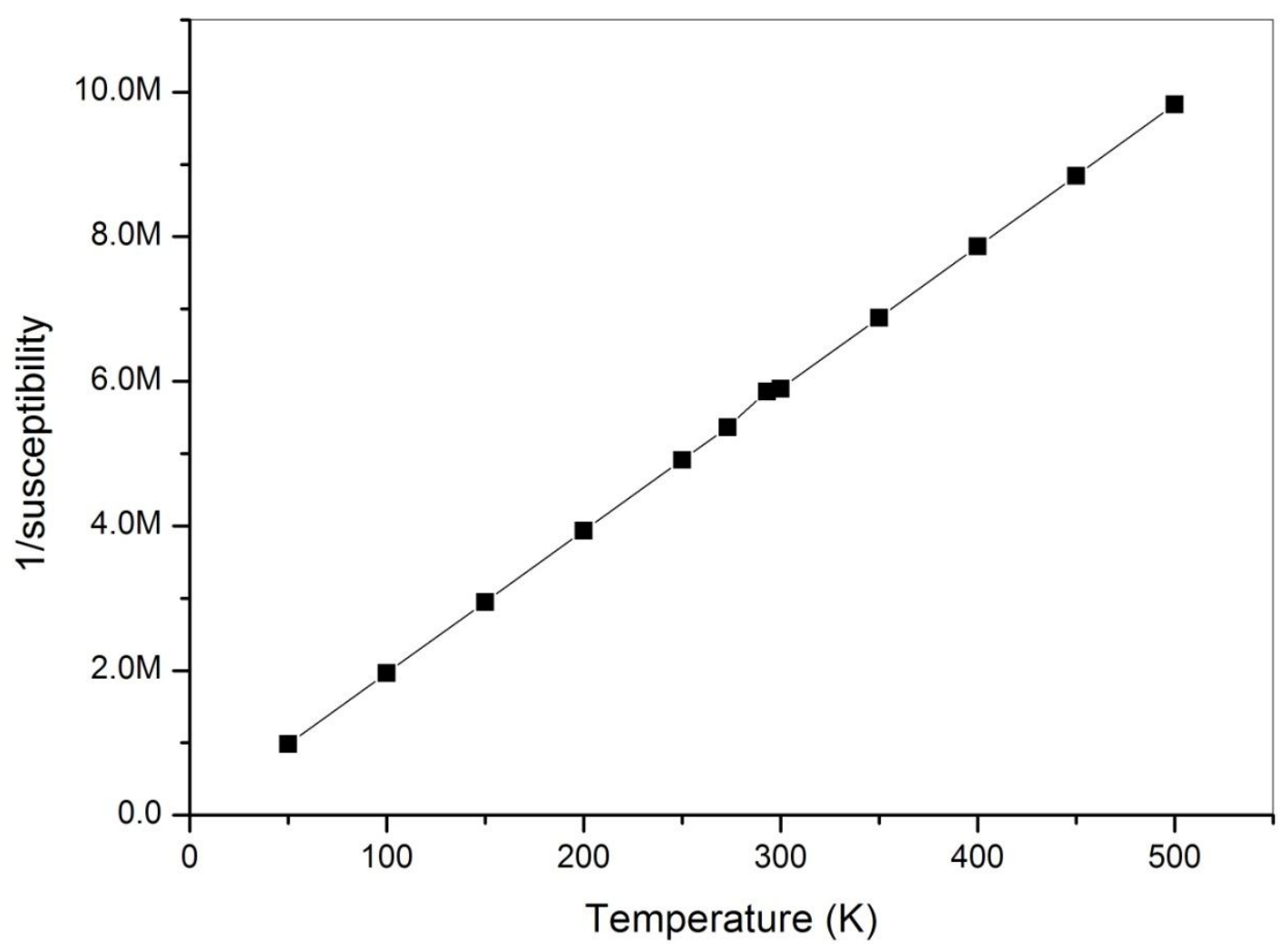

Fig 20:- The magnetic 1/susceptibility for methyl-2-chloronicotinate. 


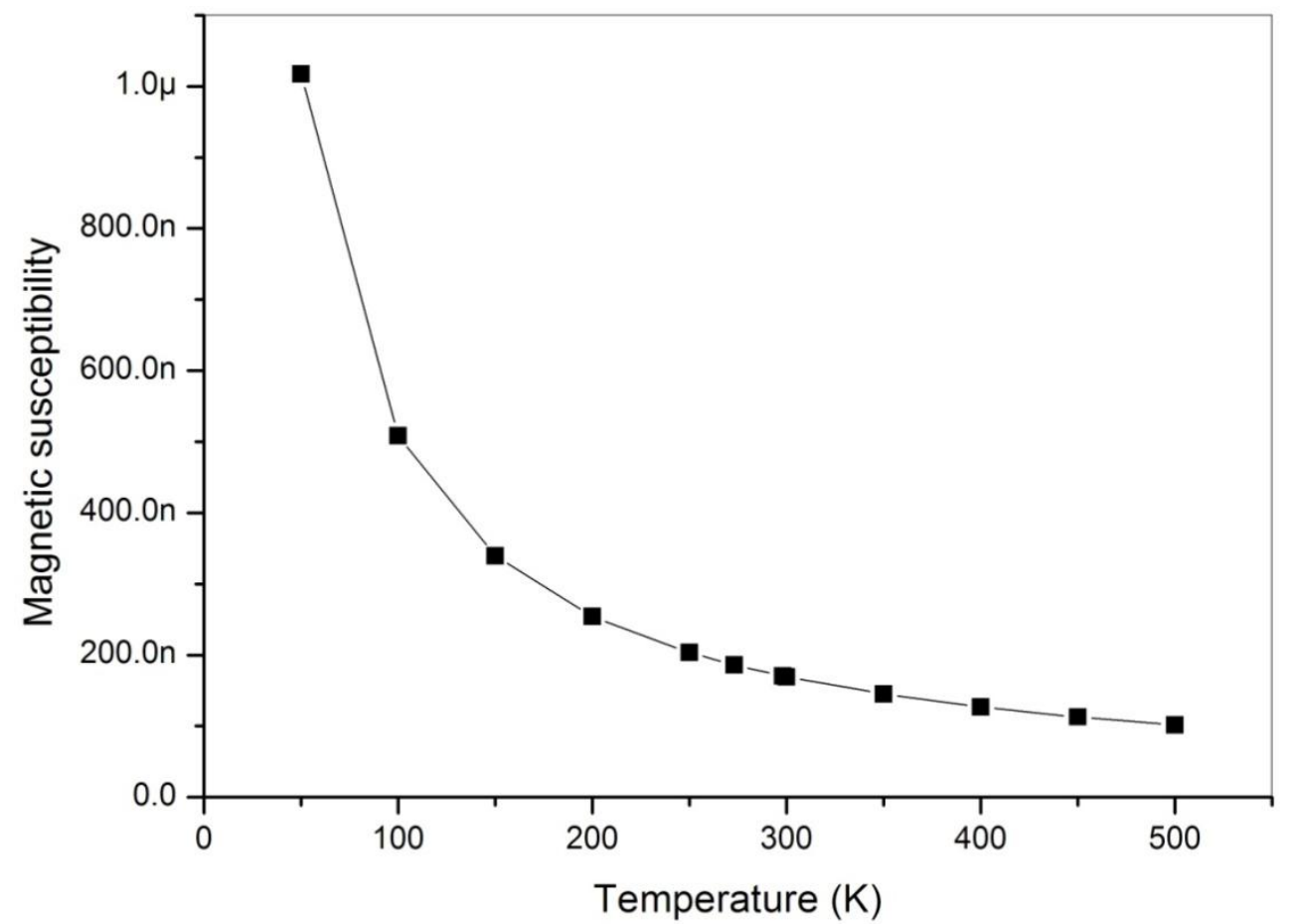

Fig 21:- The magnetic susceptibility for methyl-2-chloronicotinate.

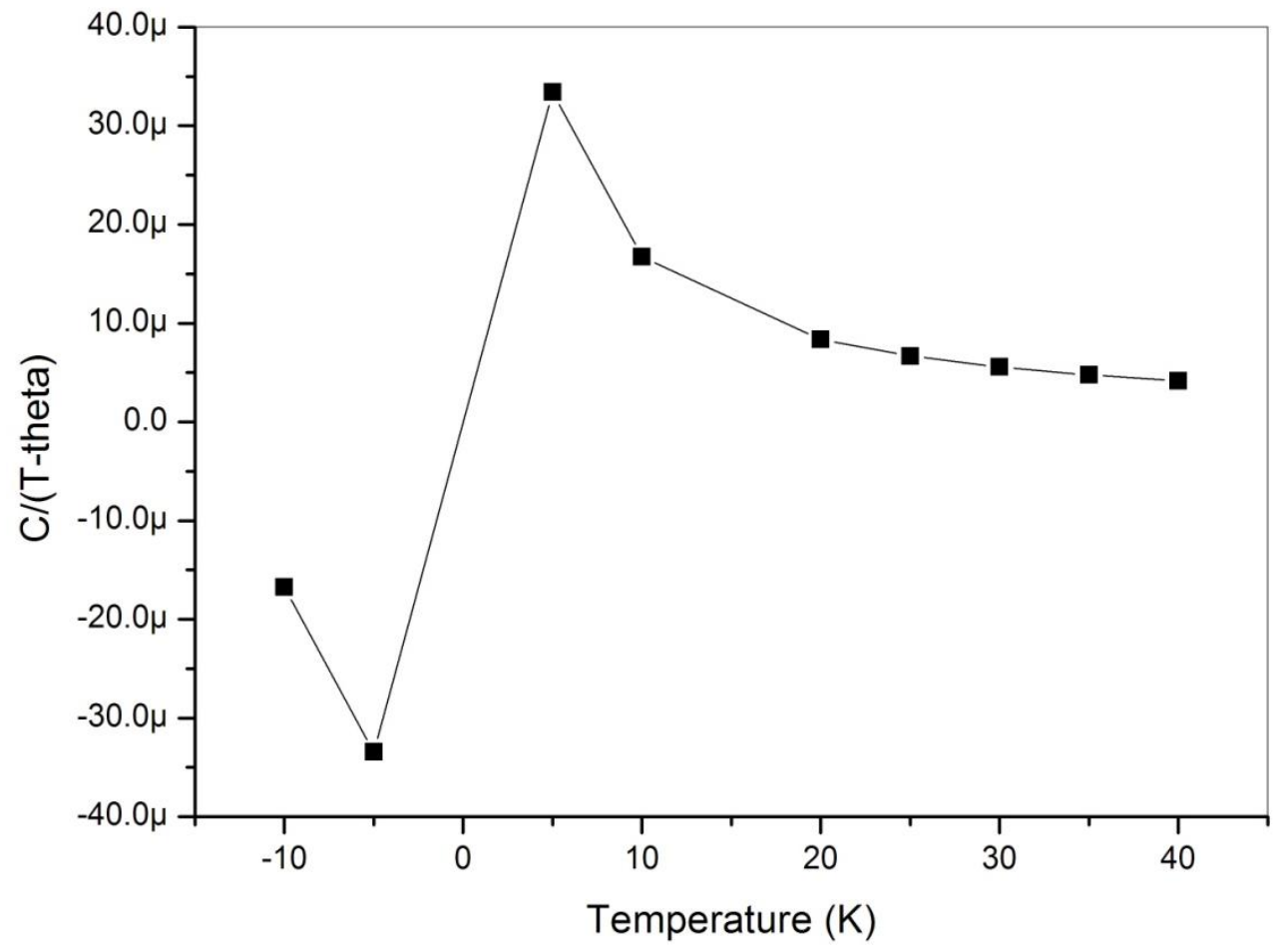

Fig 22:-The magnetic C / (T-theta)for methyl-2-chloronicotinate. 


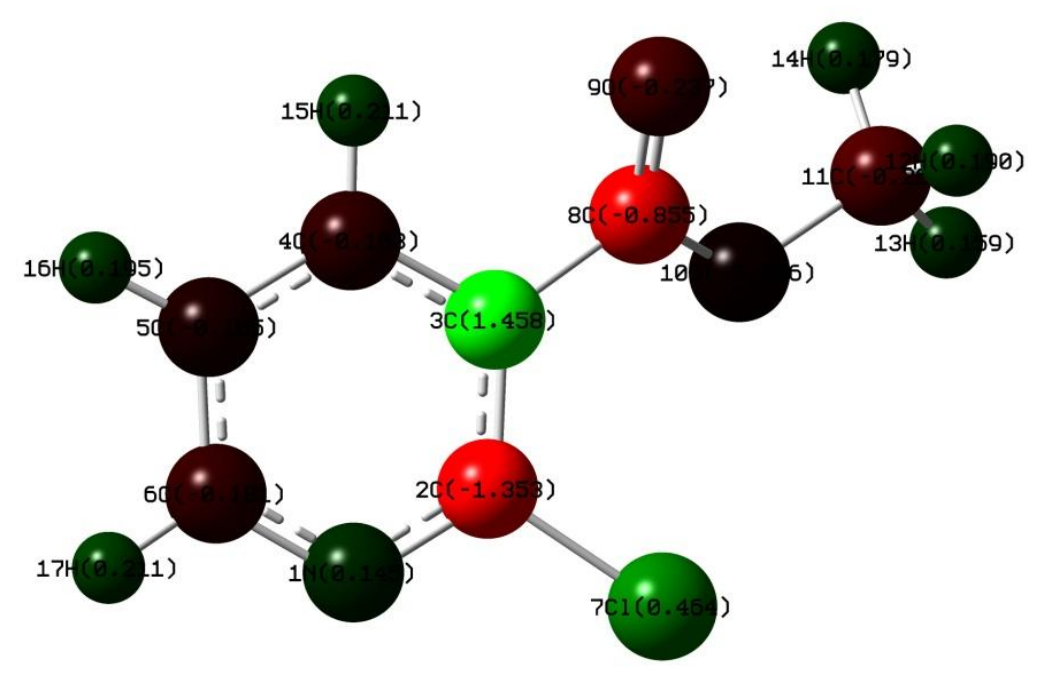

Fig 23:- The Mulliken charges distributionfor methyl-2-chloronicotinate.

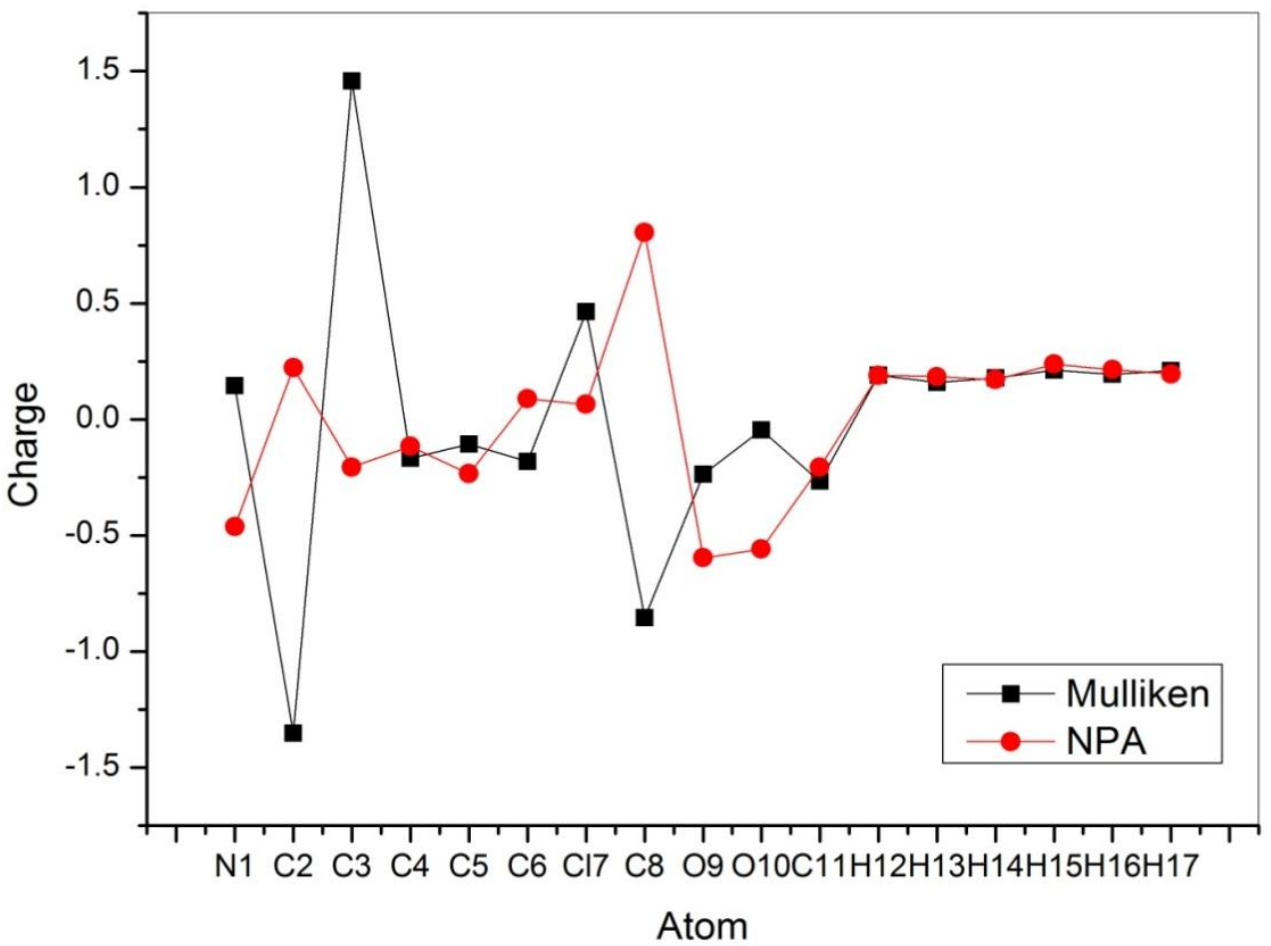

Fig 24:- Mulliken atomic charge and Natural Population Analysis Plot for methyl-2-chloronicotinate. 


\section{Conclusion:-}

FT-IR and FT-Raman spectroscopies and were performed on methyl 2-chloronicotinatein order to identify its structural and spectroscopic properties. A complete vibrational analysis of methyl 2-chloronicotinate was performed usingthe basis of $a b$ initioDFT calculation based on B3LYP level with the standard basis sets 6- 311++G (d, p). Comparison between the calculated and experimental structural parameters indicated that B3LYP was in good agreement with experimental observations. Complete vibrational analysis of methyl 2-chloronicotinate has been investigated by FT-IR and FT-Raman spectroscopy. The intermolecular hydrogen bond in dimer structure was also analyzed. The effects of hydrogen bond due to dimerization were discussed with the natural atomic hybridization. The role of nitro and carboxylic group in the vibrational frequencies of the title compound has been studied. NBO analysis has also been performed on methyl 2-chloronicotinate molecule, in order to elucidate intermolecular hydrogen bonding, intermolecular charge transfer, rehybridization and delocalization of electron density. Thermodynamic parameters were calculated theoretically for the range 100-1000 K. The electric dipole moments and the first order hyperpolarizability of the compound have been calculated by DFT method. Quantum chemical parameters such as HOMO, LUMO, energy gap, hardness ( $\eta$ ), softness (S), electron affinity (A), ionization potential $(\mathrm{I})$, absolute electronegativity $(\chi)$ and electrophilicity $(\omega)$ were calculated. The NMR-chemical shielding anisotropy (CSA) parameters of methyl 2-chloronicotinate have been computed.

\section{Reference:-}

1. D. Kovala-Demertzi, A. Theodorou, M.A. Demertzis, C.P. Raptoulou,A. Terzis, J. Inorg. Biochem.65 (1997) 151.

2. A. Albert, Selective Toxicity, ThePhysico-Chemical Basis of Therapy, 6th ed., Chapman And Hall, London, 1979.

3. M.N. Hughes, The Inorganic Chemistry of Biological Processes, 2nd ed., Wiley, New York, 1981.

4. Agilent (2011). CrysAlisPRO.Agilent Technologies, Yarnton, England.Dolomanov, O.V., Bourhis, L. J., Gildea, R. J., Howard, J. A. K. \&Puschmann, H. (2009). J. Appl. Cryst. 42, 339-341.

5. Gonza' lez, M. A., Correa-Royero, J., Mesa, A. \&Betancur-Galvis, L. (2009). Nat. Prod. Res. 23, 1485-1491.

6. Ma, Y. \& Liu, Y.-L. (2008). ActaCryst. E64, o1072.Macrae, C. F., Edgington, P. R., McCabe, P., Pidcock, E., Shields, G. P., Taylor,R., Towler, M. \& van de Streek, J. (2006). J. Appl. Cryst. 39, 453-457.

7. Rekha, V. V., Ramani, M. V., Ratnamala, A., Rupakalpana, V.,Subbaraju, G. V., Satyanarayana, C. \& Rao, C. S. (2009). Org. Process Res. Dev. 13, 769-773.

8. Sheldrick, G. M. (2008). ActaCryst. A64, 112-122.

9. Z. He, Z.M. Wang, S. Gao, C.H. Yan, Inorg. Chem. 45 (2006) 6694;

10. M.L. Bonnet, C. Aronica, G. Chastanet, G. Pilet, D. Luneau, C. Mathoniére, R. Clérac, V.Robert, Inorg. Chem. 47 (2008) 1127;

11. A. Escuer, F.A. Mautner, M.A.S. Goher, M.A.M. Abu-Youssef, R. Vicente, Chem.Commun. (2005) 605;

12. J.P. Zhao, B.W. Hu, E.C. Sañudo, Q. Yang, Y.F. Zeng, X.H. Bu, Inorg. Chem. 48(2009) 2482;

13. C.I. Yang, W. Wernsdorfer, G.H. Lee, H.L. Tsai, J. Am. Chem. Soc. 129 (2007)456;

14. Y.F. Zeng, F.C. Liu, J.P. Zhao, S. Cai, X.H. Bu, J. Ribas, Chem. Commun. (2006)2227.

15. J.Y. Zhang, C.M. Liu, D.Q. Zhang, S. Gao, D.B. Zhu, Inorg. Chem. Commun. 10(2007)897;

16. E.Q. Gao, S.Q. Bai, Y.F. Yue, Z.M. Wang, C.H. Yan, Inorg. Chem. 42 (2003) 3642;

17. R. Cortés, M. Drillon, X. Solans, L. Lezama, T. Rojo, Inorg. Chem. 36 (1997) 677;

18. M.A.M. Abu-Youssef, A. Escuer, D. Gatteschi, M.A.S. Goher, F.A. Mautner, R.Vicente, Inorg. Chem. 38 (1999) 5716;

19. M. Villanueva, J.L. Mesa, M.K. Urtiaga, R. Cortés, L. Lezama, M.I. Arriortua, T.Rojo,Eur. J. Inorg. Chem. (2001) 1581 ;

20. M.A.M. Abu-Youssef, A. Escuer, M.A.S. Goher, F.A. Mautner, R. Vicente, Eur. J.Inorg. Chem. (1999) 687;

21. R. Cortés, M.K. Urtiaga, L. Lezama, J.I.R. Larramendi, M.I. Arriortua, T. Rojo, DaltonTrans. (1993) 3685;

22. S.S. Tandon, L.K. Thompson, M.E. Manuel, J.N. Bridson, Inorg. Chem. 33 (1994)5555;

23. L.K. Thompson, S.S. Tandon, M.E. Manuel, Inorg. Chem. 34 (1995) 2356;

24. S. Sikorav, I. Bkouche-Waksman, O. Kahn, Inorg. Chem. 23 (1984) 490;

25. O. Kahn, T. Mallah, J. Gouteron, S. Jeannin, Y. Jeannin, Dalton Trans. (1989)1117.

26. I.L. Finar, Organic Chemistry. The Fundamental Principles, fifth ed., vol. 1, the English Language Book Society and Longman Group Limited, 1967.

27. P. Bosshard, C.H. Eugster, Adv. Heterocycl. Chem. 7 (1966) 377.

28. D. Faulkner, J. Nat. Prod. Rep. 1 (1984) 551-598. 
29. S.M. Kupchan, M.A. Eakin, A.M. Thomas, J. Med. Chem. 101 (1971) 1147-1152.

30. M.M. Bandurraga, W. Fenical, S.F. Donovan, J. Clardy, J. Am. Chem. Soc. 104(1982)6463-6465.

31. S.F. Schnittger, L. DeClerq (E-L Management Corp, USA), US Ser No 08/896, 194 (July 17, 1997) and US Patent No 6, 387,947 (May 15, 2002).

32. M. Hirayama, Y. Tomota, M. Hirano, K. Tachibana T. Adachi, Japan KokaiTokkyaKoho, 1992, JP 04342507.

33. H.J. Frisch, G.W. Trucks, H.B. Schlegel, G.E. Scuseria, M.A. Robb, J.R. Cheeseman, H. Nakatsuji, M. Caricato, X. Li, H.P. Hratchian, K. Toyota, R. Fukuda, J. Hasegawa, M. Ishida, R. Nakajima, Y. Honda, O. Kilao, H. Nakai, T. Verven, J. A. Montgomery Jr., J.E. Peralta, F. Ogliaro, M. Bearpark, J. J. Heyd, E. Brothers, K. N. Kudin, V.N. Staroveror, R. Kobayashi, J. Normand, K. Ragavachari, A. Rendell, J.C. Burant, S. J. Tomasi, M. Cossi, N. Rega, J. M. Millam, M. Klene, $\quad$ J. E. Knox, J. B. Cross, V. Bakken, C. Adamo, J. Jaramillo, R. Gomperts, R.E. Strattmann, O. Yazyev, A.J. Austin, R. Cammi, J.W. Ochetrski, R.L. Martin, K. Morokuma, V.G. Zakrazawski, G.A.Votn, P. Salvador, J.J. Dannenberg, S. Dapprich, A.D. Daniels, O. Farkas, J.B. Foresman, Gaussian O.G., Revision A.O2, Gaussian Inc., Wallingford, CT. 2009.

34. C. Lee, W. Yang, R.G. Parr, Phys. Rev. 1377 (1998) 785-789.

35. H. Inouse, M.Hlda, N.Nakashlma, K.Yashlhara, J. Phys. Chem., 86 (1982) 3184.

36. M.J. Frisch, A.B. Nielsm, A.J. Holder, Gaussview User Manual, GaussianPitsburgh, 2008.

37. J. Baker, A.A. Jarzecki, P. Pulay, J. Phys. Chem. A 102 (1998) 1412-1419.

38. P. Pulay, G. Fogarasi, F. Pang, J.E. Boggs, J. Am. Chem. Soc. 101 (1979) 2550-2560.

39. M.H. Jamróz, Vibrational Energy Distribution Analysis VEDA 4, Warsaw, 2004.

40. P.L. Polavarapu, J. Phys. Chem. 94 (1990) 8106-8112.

41. G. Keresztury, S. Holly, J. Varga, G. Besenyei, A.Y. Wang, J.R. Durig, Spectrochim. Acta A 49 (1993) $2007-$ 2015.

42. F.R. Dollish, W.G. Fateley, F.F. Bentely, Characteristic Raman Frequencies on Organic Compounds, John Wiley, New York, 1997.

43. R.M. Silverstein, G. ClaytonBassler, T.C. Morril, Spectroscopic Identification of Organic Compounds, John Wiley, New York, 1991.

44. G. Varsanyi, Vibrational Spectra of Benzene Derivatives, Academic Press, New York, 1969.

45. A. Lakshmi, V. Balachandran, A. Janaki, J. Mol. Struct. 1004 (2011) 51-66.

46. V. Krishnakumar, R. Mathamal, J. Raman Spectrosc. 40 (2009) 264-271.

47. M.C. Ruiz Delgado, V. Hernandez, J. Casado, J.T. Lopez Navarre, J.M. Raimundo, P. Blanchard, J. Roncali, J. Mol. Struct. 651-653 (2003) 151-158.

48. J.P. Abraham, D. Sajan, V. Shettigar, S.M. Dharmaprakash, I. Nemec, I.H. Joe, V.S. Jayakumar, J. Mol. Struct. 917 (2009) 27-36.

49. T. Vijayakumar, I. Hubert Joe, C.P.R. Nair, V.S. Jayakumar, Chem. Phys. 343(2008) 83-99.

50. M.A. Palafox, Int. J. Quantum Chem. 77 (2000) 661-684.

51. I. Fleming, Frontier Orbitals and Organic Chemical Reactions, John Wiley and Sons,New York, 1976.

52. T. Karakurt, M. Dincer, A.C. etin, M. Sekerci, Spectrochim. Acta 77A (2010) 189-198.

53. C.H. Choi, M. Kertesz, J. Phys. Chem. A 101 (1997) 3823-3831.

54. R.F. Asbury, J.A. Blessing, P.J. DiSaia, J. Malfetano, Aminothiadiazole (NSC 4728)in patients with advanced nonsquamous carcinoma of the cervix. A phase IIstudy of the Gynecologic Oncology Group, Am. J. Clin.Oncol. 12 (1989) 375-377.

55. F. Vergne, P. Bernardelli, E. Lorthiois, N. Pham, E. Proust, Ch. Oliveira, A.K.Mafroud, F. Royer, R. Wrigglesworth, J.K. Schellhaas, M.R. Barvian, F. Moreau,M. Idrissi, A. Tertre, B. Bertin, M. Coupe, P. Berna, P. Soulard, Discovery ofthiadiazoles as a novel structural class of potent and selective PDE7 inhibitors.Part 1: Design, synthesis and structure-activity relationship studies, Bioorg.Med. Chem. Lett. 14 (2004) 4607-4613.

56. K.-Y. Jung, S.-K.Kim, Z.-G. Gao, A.S. Gross, N. Melman, K.A. Jacobson, Y.-Ch.Kim, Structure-activity relationships of thiazole and thiadiazole derivatives aspotent and selective human adenosine $\mathrm{A}[3]$ receptor antagonists, Bioorg. Med.Chem. 12 (2004) 613-623.

57. P. Bhattacharya, J.T. Leonard, K. Ry, Exploring QSAR of thiazole and thiadiazolederivatives as potent and selective human adenosine A3 receptor antagonistsusing FA and GFA techniques, Bioorg. Med. Chem. 13 (2005) 1159-1165.

58. J. J. P. Stewart, Int. J. Quantum Chem.58 (1996)133-146.

59. P. Hohenberg, W. Kohn, Phys. Rev. 136(1964) B864-B871.

60. A.D. Becke, J. Chem. Phys., 98 (1993) 5648-5652. 
61. H.W. Thomson, P. Torkington, J. Chem. Soc. 171 (1945) 640.

62. E.D. Glendening, J.K. Badenhoop, A.E. Reed, J.E. Carpenter, J.A. Bohmann, C.M.vMorales, F. Weinhold, NBO 5.0, Theoretical Chemistry Institute, University ofvWisconsin, Madison, 2001.

63. P. Politzer, J. Murray, Theor. Chem. Acc. 108 (134) (2002) 142.

64. V.K. Rastogi, M.A. Palafox, L. Mittai, N. Perica, W. Kiefer, K. Lang, P. Ohja, J. Raman Spectrosc. 38 (2007) 1227-1241.

65. EszterCzinki, G. Attila Casazar, Gabor Magyartalvi, Peter R. Schreiner, Wesley D. Allen, J. Am. Chem. Soc. 129 (2007) 1568-1577.

66. M.C. Gupta, Atomic and Molecular Spectroscopy, New Age International (P) Limited, Publishers, New Delhi, 2001. 